\title{
Effect of Surface Mechanical Treatment on Mechanical Properties and Impact Behavior of S355JR Steel
}

mounira Bouali Bourebia ( $\nabla$ mounirabourbia@gmail.com )

Centre de Recherche en Technologies Industrielles

Hamid Hamadache

Research Laboratory in Advanced Technologies and Mechanical Production (LRTAPM), Badji Mokhtar Annaba University, P.O. Box.12, 23000, Annaba, Algeria

\section{Laouar Lakhdar}

Industrial Mechanics Laboratory (LMI) Badji Mokhtar University P.O. Box.12, 23000, Annaba, Algeria

Djemili Kamila

Research Center in Industrial Technologies. CRTI. P.O.BOX 64, chéraga-16014, Algeria,

Hazem Tarek

Research Center in Industrial Technologies. CRTI. P.O.BOX 64, chéraga-16014, Algeria,

\section{Taleb Ahlem}

Research Center in Industrial Technologies. CRTI. P.O.BOX 64, chéraga-16014, Algeria,

\section{Research Article}

Keywords: Tensile resistance, burnishing, heat treatment, superficial hardness, absorbed energy, penetration depth, ruptures facies

Posted Date: March 19th, 2021

DOl: https://doi.org/10.21203/rs.3.rs-299594/v1

License: (a) (1) This work is licensed under a Creative Commons Attribution 4.0 International License. Read Full License 


\section{Effect of surface mechanical treatment on mechanical properties and impact behavior of S355JR steel}

Mounira Bourebia ${ }^{1 *}$, Hamid Hamadache ${ }^{2}$, Laouar Lakhdar ${ }^{3}$, Djemili Kamila ${ }^{1}$, Hazem Tarek $^{1}$, Taleb Ahlem ${ }^{1}$

${ }^{1}$ Research Center in Industrial Technologies. CRTI. P.O.BOX 64, chéraga-16014, Algeria,

${ }^{2}$ Research Laboratory in Advanced Technologies and Mechanical Production (LRTAPM), Badji Mokhtar Annaba University, P.O. Box.12, 23000, Annaba, Algeria.

${ }^{3}$ Industrial Mechanics Laboratory (LMI) Badji Mokhtar University P.O. Box.12, 23000, Annaba, Algeria

*Correspondence: mounirabourbia@gmail.com, m.bourbia@crti.dz; Tel:213557099738.

Abstract: Often, surface mechanical treatments (SMT) or heat (quenching, tempering) are used to improve the surface condition and mechanical characteristics such as impact resistance and tensile strength. Hence the objective of this experimental work, where ball burnishing (BB) as well as quenching and tempering were applied on S355 JR steel specimens in order to evaluate the surface hardness "Hv", the rupture strength "Rm", the energy absorbed "W" during the impact test and the work-hardened thickness "e" after the burnishing operation. Factorial designs were used for the tests organization and mathematical models were established for the prediction of "Hv", "Rm", "W" and "e" in function on treatment parameters considered: number of tool passes (i) and the pressure force (Py). The results show that the surface hardness increases by 30.46\%. The high levels of "Py" and "i" were allowed to improve "Rm" by $30.8 \%$ as well as an increase in tenacity of only $3.6 \%$. Increasing the force to $20 \mathrm{kgf}$ promotes mixed rupture under the effect of impact to shock. The quenching and tempering improve the resistance "Rm" by $183 \%$ and $119 \%$ respectively, while the effect of burnishing was limited to a rate of increase of this property of $28 \%$ compared to machining.

Keywords: Tensile resistance, burnishing, heat treatment, superficial hardness, absorbed energy, penetration depth, ruptures facies.

\section{Nomenclature}

\begin{tabular}{c|l} 
Py & Burnishing force \\
i & Number of tool passes \\
Rm & Rupture strength \\
Hv & Superficial hardness \\
W & Absorbed energy \\
e & penetration depth \\
BB & Ball Burnishing \\
X1 & Coded factors for Py \\
X2 & Coded factors for i \\
$a_{0}$ & Constant is response value at the central point of study domain; \\
$a_{1}$ & Effect of factor X1 (for Py); \\
$a_{2}$ & Effect of factor X2 (for i); \\
$a_{12}$ & The interaction between X1 and X2; \\
Y & Output response (for Rm, Hv, e and W) \\
SMT & Surface mechanical treatment \\
SB & Surface burnishing \\
RSM & Responses surface methodology \\
SPD & Surface plastic deformation
\end{tabular}




\section{Introduction}

During their commissioning, the surfaces of the parts are the most exposed to different stresses and are therefore the first to deteriorate. Thus subjected to forces (static, cyclic or dynamic) excessive, the material breaks after plastic deformations sometimes even elastic. In most cases the rupture beginning, on the surface. Friction work causes the loss of operating power after wear of the pieces surfaces. Working in an aggressive environment degrades the material by corrosion phenomenon that starts on the surface [1, 2]. Therefore, surface integrity is generally considered an important aim in manufacturing processes to predict service properties and pieces lifetime [3]. Therefore, thorough finishing techniques are needed to rectify the surface integrity after machining which is particularly difficult [4-6].

To increase the performance and service life of mechanical pieces, the industrial sector, of course, relies on good physical and geometric surface quality by integrating into the pieces manufacture several surface finishing techniques by chip removal (grinding, running-in ... ) and by applying thermal surface treatments (quenching, tempering, annealing) [7, 8] or thermochemical diffusion processes (nitriding, carburizing) [9]. However, these techniques are often slow and expensive, time-consuming and not ecological and can generate significant residual tensile stresses as well as changes in the structure of the material which can cause certain defects [10]. In addition, these methods are not sufficiently efficient with regard to the fatigue behavior of metallic components. This is why they are increasingly combined with other SMT methods [11-14].

These SMT techniques are increasingly used to modify surface integrity. They differ according to their impacts without any alteration in chemical composition. Such treatments (SMT) such as shot blasting, roller burnishing, ball burnishing operate by surface plastic deformation (SPD) and without removal (carried out without loss of material) of material. Due to the simplicity of devices they use and the relatively short time of their operations, PSD's processes provide a relatively significant economic benefit for improving the surface integrity of the material at a lower cost.

The BB process [15- 20] which is part of this family is characterized by the rolling contact friction of a hydrostatic ball [9] applied to the crest of surface asperities to force them to flow as progress the tool rolls and fill in the hollows thereof. This results in a new surface integrity characterized by a reduction in the asperities height and a flattening of the roughness profile, a fibrous structure with refined grains and a hardening of superficial layers and the introduction of residual compressive stresses [21].

Ball burnishing is principally realized with mechanical and hydrostatic springs, however new tools have been developed to improve the process such as: vibration assisted burnishes and multiple ball burnished [22-24]. The effects of burnishing vary from one author to another, however, these results are attributable to the different amplitudes of the parameters studied, to the mechanical properties of the materials and to type of machine tool used [13][25-29].

- M. Kowalik and al., [30] shows that after burnishing under a pressure of the $3 \mathrm{kN}$ roller on the C45 steel, the thickness of the plastically deformed superficial layer observed under the microscope and verified by microhardness measurements has reaches $0.7 \mathrm{~mm}$ in a deformed area of $1.2 \mathrm{~mm}$.

- Hamadache and al. [31] observed following metallographic observation and micro-hardness measurements that the penetration depth reinforced by surface plastic deformation (SPD) which achieve $100 \mu \mathrm{m}$.

- V. Ferencsik and G. Varga [32] found that among the parameters examined, the effect of burnishing force is the most dominant. In addition, on the basis of Taguchi plan, they identified the parameters which favor the best improvement in microhardness, by the fact that the tool and the piece surface are in contact with more power and a longer implementation time. 
By performing the BB operation with a $6 \mathrm{~mm}$ ball and $120 \mathrm{~N}$ and 7 passes on the AISI 1038 material this combination is a suitable for the process application in terms of improving the service life [33]. In addition, tensile tests on burnished samples were performed, achieving up to $49 \%$ improvement in material ductility. This improvement could be due to the fact that the ball burnishing process improved the surface finish, also mitigating micro-cracks on the sample edges and significantly decreasing surface defects where possible cracks could appear. Some work has shown that despite the surface hardening that it causes, burnishing does not disturb the ductility of the material too much and even keeps the elongation at break by traction after treatment and could subsequently improve the impact resistance [19, 21].

- Bounouara and al [34] observed a significant change in the energy absorbed as a function of temperature by the spiral welded and ball-burnished X70 steel samples. SEM observations of the fractured surfaces revealed that the effect of ball burnishing can affect both the surface and the core of impact sample. The burnishing force is the most important parameter on the fracture surface.

- Avilés, R. et al. [15] estimated an average hardness of $335 \mathrm{HBN}$ in the external layers treated with LPB, and by correlation a tensile strength of the hardened surface area of 1060 $\mathrm{MPa}$. Furthermore, they have found that the LPB can compress a surface layer $0.45 \mathrm{~mm}$ thick in which occur the residual stresses in the order of $-600 \mathrm{MPa}$ to a depth of $0.5 \mathrm{~mm}$. Therefore the fatigue limit increased by $21.25 \%$ after this treatment.

- J.T. Maximov and al. [35] noted that SB caused a fibrous micro structure of superficial layers characterized by grain refinement and elongation. The authors noticed an increase in fatigue limit of $40 \%$ when SB is performed with optimal parameters and $n=6$ passes.

- Jordi Lumà and al, [36] limited the vickers indentation load to $0.05 \mathrm{~kg}$ in order to avoid indentation in the material core and better exploit the effects of ball burnishing of S235 JR steel. The authors have shown that an increase in the burnishing force decreases the ductile behavior of material and increases its tensile properties despite reducing the effects of vibration assist.

The BB is most often realized with the following main parameters: the ball radius, the burnishing force, feed speed, burnishing speed and the number of passes. However, experience has shown that a combination of these factors results in different results from SI. Moreover, numerical simulation, mathematical modeling, and statistical analysis have been used by many researchers to optimize burnishing parameters and predict the best output response.

Tourab and al. [37] modeled and optimized the input variables for surface roughness and microhardness of Steel S355 JR using a central composite design based on RSM. They developed mathematical models for the output responses.

- D. Mahajan [38] used signal-to-noise ( $\mathrm{S} / \mathrm{N})$ analysis to derive an optimal combination of parameters to achieve minimum surface finish

ss applied to the experimental samples. Increasing the rotation speed and the burnishing ball diameter ensure a positive effect on the tensile strength.

M Bourebia and al. [40] used multifactor planning to predict the surface hardness and tensile properties of S355JR steel. They pointed out that Py $20 \mathrm{kgf}$ and $\mathrm{i}=3$ is the optimal combination which promotes an increase in $\mathrm{Hv}$ of $45 \%$. While a low force combined with a large number of passes hinders the ductility of the material by the effect of supersaturation in hardening.

G Basar and F. Kahraman [41] studied the effect of burnishing parameters on surface hardness using analysis of variance (ANOVA), fuzzy logic and the Taguchi technique. They found that the burnishing force and the number of passes are the most significant factors.

Ishfaq and al. [42] from at centered face composite experimental plan performed a multiple response from desirability analysis to optimize different contradictory responses. The majority 
of BB studies focus on SI study of, where the main intention, is consented on roughness and microhardness. Much less attention is grant at the impact resistance (tenacity) of materials; yet this characteristic often characterized by impact testing is an integral part of surface integrity. Thus, the objective of this work is initially to estimate the effect of burnishing through the measurement of the surface hardness (Hv) as well as breaking strength by traction $(\mathrm{Rm})$ of S355 JR steel and secondly, to see the impact behavior by evaluating the energy absorbed and also to get an idea (by correlation) on the burnished material tenacity. Thus, this study has been statistically and experimentally examined during the BB of S355JR steel. A predictive model of the hardened depth layer, hardness, breaking strength and resilience was obtained by RSM. All the output responses were evaluated based on the two main burnishing parameters namely: the force (Py) and the number of tool passes (i) of ball burnishing.

\section{Materials and Methods}

\subsection{Material}

The material used is S355 JR steel (ASTM) supplied in cylindrical bars form. The sample destined for the determination of the chemical composition and prepared according to ISO 14284: 2002. The results of chemical analysis are shown in Table 1.

Table 1. Chemical composition of S355 JR

\begin{tabular}{ccccccccccc}
\hline \multicolumn{10}{c}{ Element content\% } \\
\hline $\mathbf{C}$ & $\mathbf{S}$ & $\mathrm{Al}$ & $\mathrm{Si}$ & $\mathbf{P}$ & $\mathbf{V}$ & $\mathbf{C r}$ & $\mathbf{M n}$ & $\mathbf{N i}$ & $\mathbf{C u}$ & $\mathbf{M o}$ \\
0,188 & 0,003 & 0,0273 & 0,2314 & 0,0051 & 0,00327 & 0,1571 & 1,053 & 0,0548 & 0,0575 & 0,0297 \\
\hline
\end{tabular}

The mechanical characteristics of the material were defined using a tensile test carried out on cylindrical specimens (ISO 6892-1) and evaluated by $\mathrm{Rm}=523.6 \mathrm{MPa}, \mathrm{Re}=365.6 \mathrm{~N} / \mathrm{mm} 2$, $\mathrm{A}=30.0 \%$. The Vickers hardness is of order $\mathrm{Hv}=237.3$.

\subsection{Experimental methodology}

For esteemed the effect of burnishing parameters on different responses studied such as surface hardness $(\mathrm{Hv})$, the rupture strength $(\mathrm{Rm})$, the penetration depth (e) and the impact tenacity (W), a factorial design $2^{2}$ composed of two factors: the burnishing force (Py) and the number of tool passes (i) [43] was adopted. These parameters are coded according to experimental plan $2^{2}$ and each factor has 02 levels which indicated are shown in table 2 [14]. In this study the RSM technique which is an empirical modeling approach were used for determination of a relationship between burnishing parameters and studied responses, this relation can be expressed by the equation (1). This will allow analyze the influence of these parameters on considered responses evolution.

$$
Y=a_{0}+a_{1} X_{1}+a_{2} X_{2}+a_{12} X_{1} X_{2}
$$

Where "Y" is the response studied.

$\mathrm{a}_{0}$ : Constant is response value at the central point of study domain;

$\mathrm{a}_{1}$ : Effect of factor X1 (for Py);

$\mathrm{a}_{2}$ : Effect of factor X2 (for i);

$\mathrm{a}_{12}$ : Interaction between $\mathrm{X} 1$ and $\mathrm{X} 2$; 
Table 2 Experiment matrix

\begin{tabular}{ccc}
\hline $\begin{array}{l}\text { Test } \\
\text { order }\end{array}$ & \multicolumn{2}{c}{ Coded factors } \\
\hline & $\mathrm{X}_{1}(\mathrm{Py})$ & $\mathrm{X}_{2}(\mathrm{i})$ \\
$\mathbf{1}$ & -1 & -1 \\
$\mathbf{2}$ & +1 & -1 \\
$\mathbf{3}$ & -1 & +1 \\
$\mathbf{4}$ & +1 & +1 \\
\hline & & \\
level -1 & 10 & 1 \\
level +1 & 20 & 3 \\
\hline
\end{tabular}

\subsection{Burnishing operation}

To conform at factorial design $2^{2}$, four Charpy $\mathrm{V}$-notch specimens were prepared on a universal milling machine according to ISO 6892-1: 2016.

The surface treatment of impact specimens has been achieved mechanically using a ball burnishing tool on a vertical milling machine. The tool used for this was designed and manufactured by Bounouara and al. [34]. The burnishing process consists at exercise a pressure with a ball on the piece surface as to get a plastic deformation on the whole surface to be burnished. The operation was carried out under abundant lubrication by means of an SAE20 oil emulsion. Other parameters like brooch rotation frequency $(\mathrm{N})$ and feed rate (f) which affect the application of ball burnishing were held constant at $100 \mathrm{rpm}$ and $0.05 \mathrm{~mm} /$ rev respectively. The choice of these values takes into account the results obtained after previous work [31]. The kinematics of BB is the same as those of milling (Fig. 1). After the burnishing operation, exploratory superficial hardness (Hv) measurements have been conducted on impact specimens using a Vickers model Matsuzawa hardness testing machine (MXT70) under an indentation load of $3 \mathrm{kgf}$ for $15 \mathrm{~s}$. The rupture strength $(\mathrm{Rm})$ of the superficial layers is directly correlated from the measured hardness. The hardness values and therefore that of the $(\mathrm{Rm})$ were obtained by averaging the three readings. The thickness of hardened layer (e) was measured using a Nikon ECLIPSELV150N type optical microscope.

The impact tests were carried out on a pendulum-type machine (Zwick brand and HIT50P model) with a maximum capacity of $50 \mathrm{~J}$, at ambient temperature. The energy absorbed (W) for breaking each test specimen was recorded. All the measured output responses are reported in Table 3.

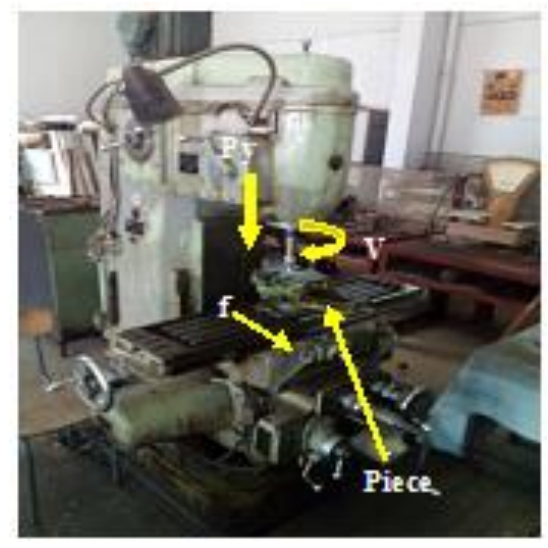

Figure 1. Burnishing device mounted on a milling machine 
Table 3. Experiment matrix and output responses measured after burnishing

\begin{tabular}{ccccccc}
\hline \multirow{2}{*}{$\begin{array}{c}\text { Test } \\
\text { order }\end{array}$} & \multicolumn{2}{c}{ Input parameters } & \multicolumn{4}{c}{ Output responses } \\
\cline { 2 - 7 } & \multicolumn{2}{c}{ Naturels factors } & $\mathrm{Y}_{\mathrm{Hv}}$ & $\mathrm{Y}_{\mathrm{Rm}}$ & $\mathrm{Y}_{\mathrm{W}}$ & $\mathrm{Y}_{\mathrm{e}}$ \\
& $\mathrm{P}_{\mathrm{y}} \quad$ (i) (passes) & $\mathrm{Hv}$ & $\mathrm{Rm}$ & $\mathrm{W}$ & $\mathrm{e}$ \\
& $(\mathrm{kgf})$ & & & $(\mathrm{MPa})$ & $(\mathrm{J})$ & $(\mu \mathrm{m})$ \\
$\mathbf{1}$ & 10 & 1 & 215,46 & 687,66 & 197 & 319,52 \\
$\mathbf{2}$ & 20 & 1 & 222,43 & 708,00 & 180 & 157,46 \\
$\mathbf{3}$ & 10 & 3 & 243,06 & 774,00 & 193 & 222,42 \\
$\mathbf{4}$ & 20 & 3 & 236,13 & 791,66 & 162 & 143,33 \\
\hline
\end{tabular}

\subsection{Heat treatments}

The heat treatments were carried out in a model Fumace 40000 oven. Quenching was carried out at a temperature of $900{ }^{\circ} \mathrm{C}$ maintained for $60 \mathrm{~min}$ and cooled in oil. After that, the samples were subject at tempering $300{ }^{\circ} \mathrm{C}$ for $10 \mathrm{~min}$ followed by air cooling. The mean values of "Hv" and "Rm", corresponding are recorded in Table 4.

Table 4 Values measured for $\mathrm{Hv}$ and $\mathrm{Rm}$ after heat treatment

\begin{tabular}{ccc}
\hline & Quenching & Tempering \\
\hline Hv & 522.73 & 410.86 \\
$\mathbf{R m}(\mathbf{M P a})$ & 1712.66 & 1326 \\
\hline
\end{tabular}

\section{Interpretation and discussion of the results}

\subsection{Comparison between the effect of heat treatment and mechanical surface treatment}

The influence of each treatment process on the superficial hardness $\mathrm{Hv}$ and the rupture strength $\mathrm{Rm}$ illustrated in Fig. 2 shows that the effect of heat treatment is more significant than that of burnishing. On one hand, the surface hardness is improved by $182 \%$ and $122 \%$ after quenching and tempering respectively. On the other hand, these same heat treatments improve the resistance "Rm" by $183 \%$ and $119 \%$ respectively, whereas the effect of burnishing was limited to a rate of increase of this property of $28 \%$ compared to machining. This phenomenon is explained by the fact that the heat treatments affect the material at the core while the burnishing which is a surface mechanical treatment applies only to superficial layers of the material [.].

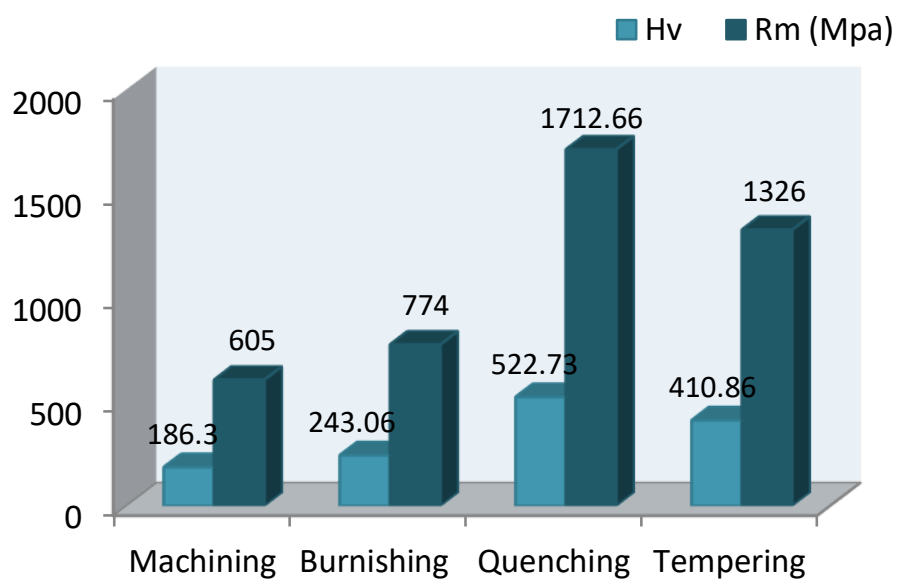

Figure 2. Effects of heat treatments on the properties of S355JR steel. 


\subsection{Overall effect of burnishing on "W", "Hv" and "Rm"}

In view of plastic deformation of the superficial layers that it confers to the material, ball burnishing allows an apparent improvement in certain mechanical properties. The beneficial effects of the process were noted for all the combinations of parameters (Py and i) considered in this study (Fig. 3). In fact, by combining the low level of burnishing force (Py $=10 \mathrm{kgf})$ with the high level of the number of tool passes ( $i=3)$, the surface hardness is improved by $30 \%$ compared to the machined state. Furthermore, it is found that the breaking strength increases along with the increase in hardness. This can be explained by the fact that the passage of ball under pressure piles up the superficial layers giving a structure with elongated grains [35]. Initially, this phenomenon improves the hardness at the surface and consequently increases the tensile strength of superficial layers. By pushing the force to its high level (Py = $20 \mathrm{kgf}$ ), the material appears more ductile and although a slight decrease in hardness has been recorded, the superficial layers have consolidated so that their tensile strength has improved by $30.8 \%$. Such improvement generally contributes to improving the fatigue and wear resistance of materials [15]. It follows in this same condition of burnishing (20kgf and 3passes), a slight increase in the impact toughness of material which requires approximately (3.8\%) more energy compared to its machining state to break. Probably the BB introduces the residual compressive stresses which tend to close the microcracks and prevent their propagation [33].

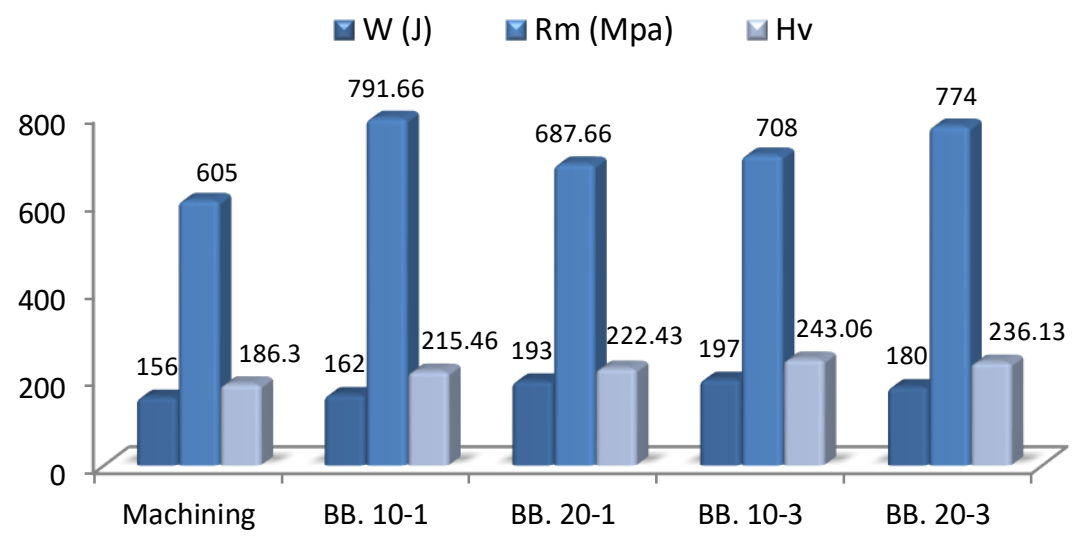

Figure 3. Burnishing effects on the properties of S355JR steel.

\subsection{Evolution of the penetration depth after burnishing}

FIG. 4 illustrates the evolution in the penetration depth on burnished samples under different burnishing conditions, where it is observed that the process affects a more or less significant deformed layer depending on the parameters applied. Thus, the optimal combination which affects the material more in depth $(\mathrm{e}=319.52 \mu \mathrm{m})$ is characterized by low levels of "Py" and "i" which interact with each other. However, by pushing these parameters to their maximum levels, the depth of penetration achieve a value $(\mathrm{e}=143.33 \mathrm{mum})$ due to the supersaturating in hardening of the superficial layers.

On the other hand, the evolution of the energy absorbed (W) as a function of penetration depth (Fig 5) shows an increase in energy with the depth affected by burnishing until reaching $157.46 \mu \mathrm{m}$ beyond this depth the energy undergoes a quasi-stationary evolution, where rupture energy records a maximum value of $197 \mathrm{j}$ for a depth of $319.52 \mu \mathrm{m}$. We are therefore led to conclude that the more thickness (depth) of the hardened layer is important; the more the material tends to regain its ductility and thus absorbs more energy to break by impact. 


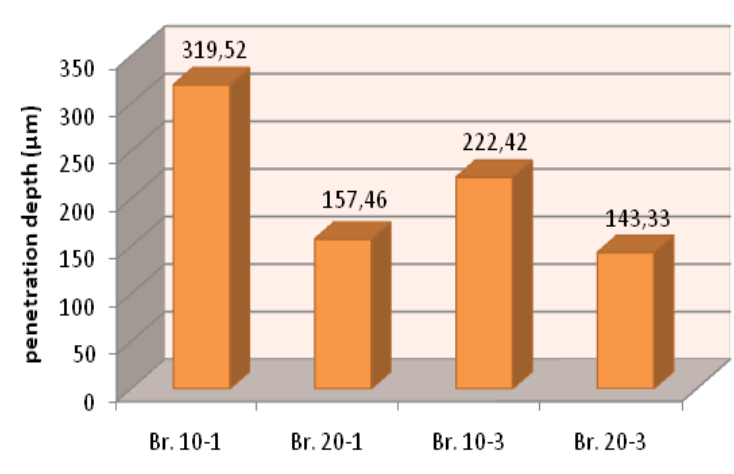

Figure 4. Effects of burnishing parameters on the penetration depth (e).

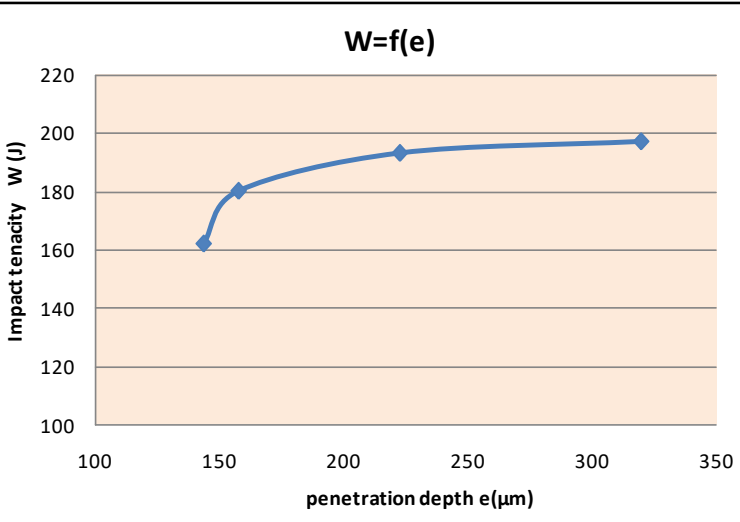

Figure 5. Evolution of the energy absorbed (W) as a function of penetration depth

The penetration depth "e" was measured using an optical microscope of the NIKON LV150N type. Indeed, the passage of the burnishing ball modifies the phenomenological appearance of the surface to a depth of up to $319.52 \mu \mathrm{m}$ for "Py" and "i" taken at their low levels. Hence, the micrograph shows microcracks that infiltrate the surface (Fig. 6a); this is probably due to present the defects on the initial surface. By pushing "Py" to its high level (20 kgf), the surface of the material is less affected $(e=157.46 \mu \mathrm{m})$ on which spalling forms (Fig. 6b). So, the surface layers are more hardened under the load effect and therefore, consume less energy to break by impact. On the other hand, when increasing the number of tool passes $(i=3)$, we observe a clear interaction of this parameter with the burnishing force (Py) from the point of view of the penetration depth (e) which increases when applies low force. The surface presents a disturbed relief with the formation of crevices and bulges of material and the sample consumes more energy to rupture (Fig. 6c). Moreover, for high levels of the burnishing parameters, the affected surface layers are the least deep (e = 143.35J) and therefore less tenacious to impact. The surface micrograph shows traces of the readable burnishing ball (Fig. 6d).

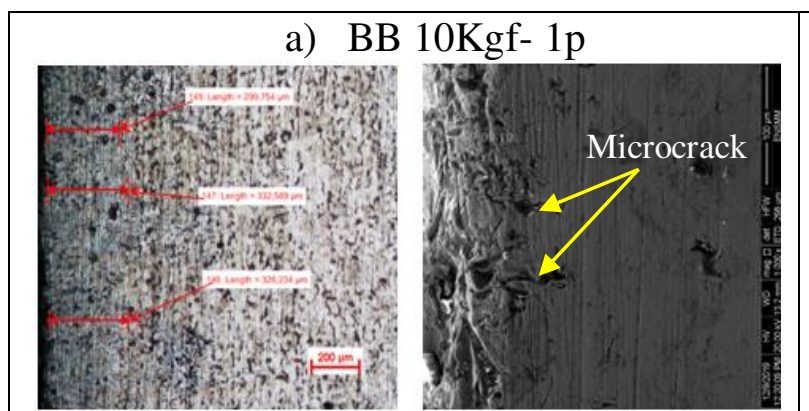

c) BB $10 \mathrm{Kgf}-3 \mathrm{p}$
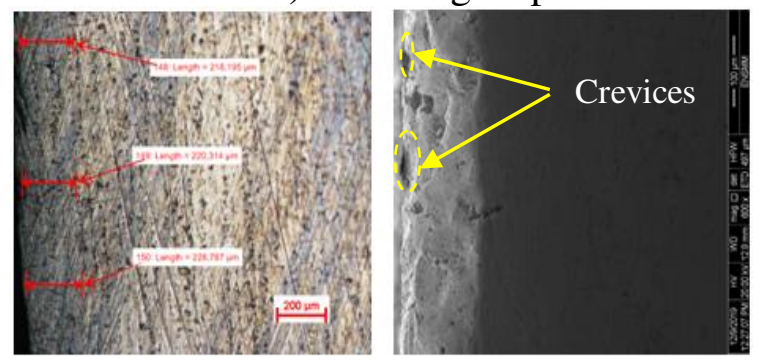

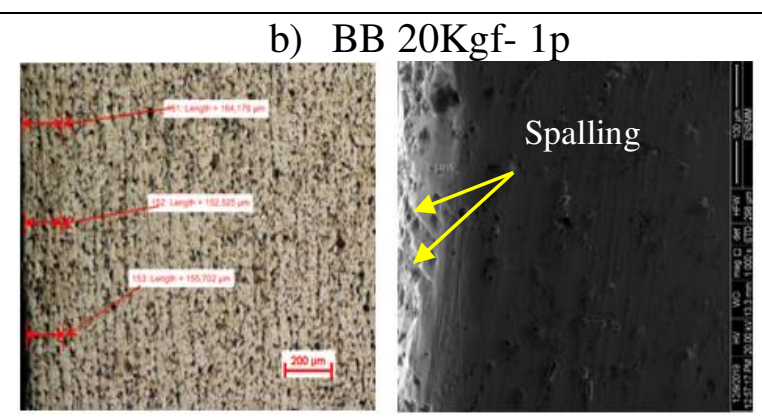

d) BB 20Kgf- 3p

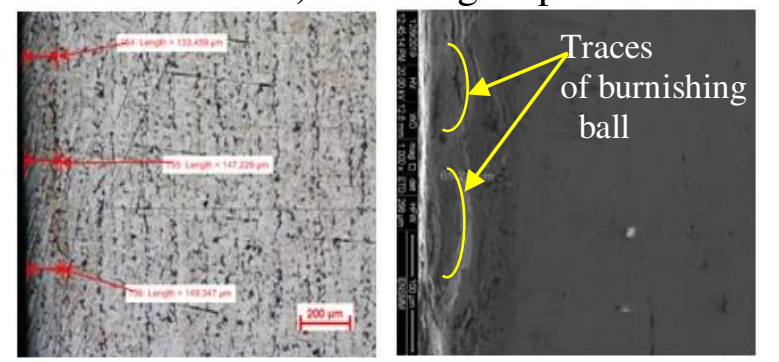

Figure 6. Micrograph of hardened superficial layer by burnishing 


\subsection{Modeling of output responses}

The relationship between the factors and the performance measures was modeled by linear regression. The regression equations obtained are given below by Eqs $(2,3,4,5)$. These equations have been validated by acceptable correlation coefficients $\left(\mathrm{R}^{2}\right)$ as shown in the figures below (Fig. 7). The regression models are allow predicting the responses output with respect to the input parameters.

$$
\begin{aligned}
& H v=187,7+1,392 \mathrm{Py}+20,75 \mathrm{i}-0,6950 \mathrm{Py} * \mathrm{i} \\
& R m=622,8+2,168 \mathrm{Py}+44,51 \mathrm{i}-0,1340 \mathrm{Py} * \mathrm{i} \\
& W=209,0-1,000 \mathrm{Py}+5,000 \mathrm{i}-0,7000 \mathrm{Py} * \mathrm{i} \\
& e=571,6-20,35 \mathrm{Py}-90,04 \mathrm{i}+4,149 \mathrm{Py} * \mathrm{i}
\end{aligned}
$$

The above models can be used to predict the responses ( $\mathrm{Rm}, \mathrm{Hv}, \mathrm{W}$ and e) at any point of the study domain covered by the factors X1 (for Py) and X2 (for i).

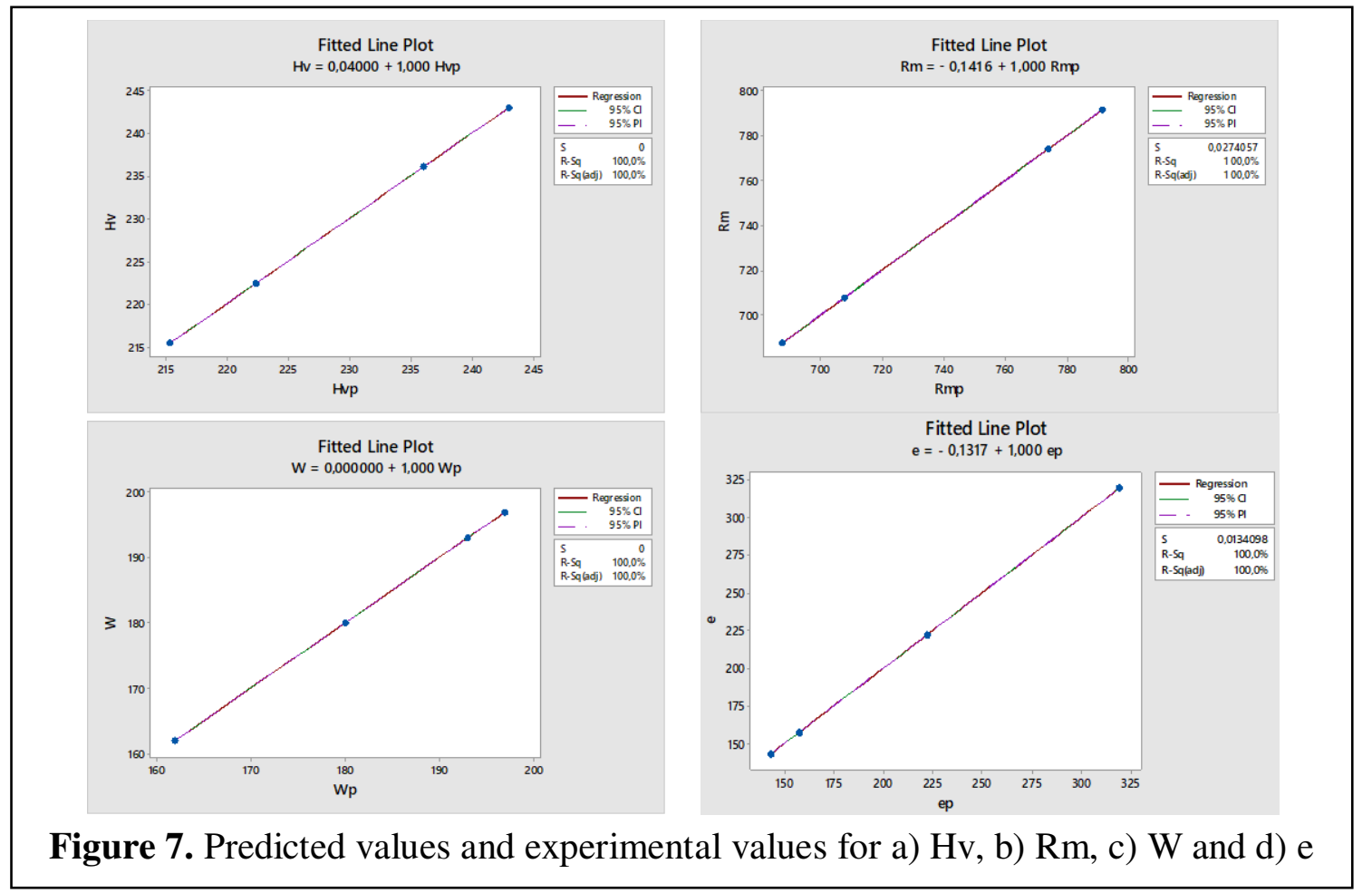

\subsection{Interactions effect on responses (3Dplots and contours)}

The response surfaces illustrating the variation of the responses studied (Hv, Rm, W, e) as a function of burnishing parameters (Py, i) (Fig 8). The graphics show that the effect of the number of tool passes "i"on the surface hardness "Hv" and rupture strength "Rm" are more significant compared to burnishing force "py", where it clearly appears that " $\mathrm{Hv}$ " is all more improved, as the number of tool passes increases $(i=3)$ in particular for low loads [40]; which reaches a value of $243.06 \mathrm{Hv}$ (Fig 8a). Likewise, the rupture strength "Rm" increases considerably with the increase in the number of tool passes (Fig. 8b). This can be explained by the fact that applying several passes further strengthens the material by increasing the tensile strength of its superficial layers. 
Furthermore, it is observed (Fig 7c) that whatever the number of passes associated with a low load, the energy absorbed "W" during the impact test increases to its maximum to reach a value of $197 \mathrm{~J}$. This is probably due to ductility of the material which requires more energy to break [19]. While, the use of burnishing parameters at their maximum levels causes a decrease in energy because the material is more fragile due to over-hardening of superficial layers.

In addition, it is found according to the graphic of figure $7 \mathrm{~d}$ that penetration depth "e" increases as the load and the number of tool passes are reduced simultaneously which further affects the material. While by maintaining, the load at its minimum level, the penetration depth "e" decreases with the increase in the number of tool passes. In the same manner, by increasing load and regardless of the number of passes applied, the superficial layers are crushed under the effect of the load resulting in a decrease in the penetration depth "e".

The other hand, contour graphs are shown in Fig 9. They visualize the response surface and also allow establishing the response values. The diagram shows the relationship between a response value (in our case $\mathrm{Hv}, \mathrm{Rm}, \mathrm{W}$ and e) and two factors of an equation model. The points having the same response are joined to generate the contour lines consistent responses.
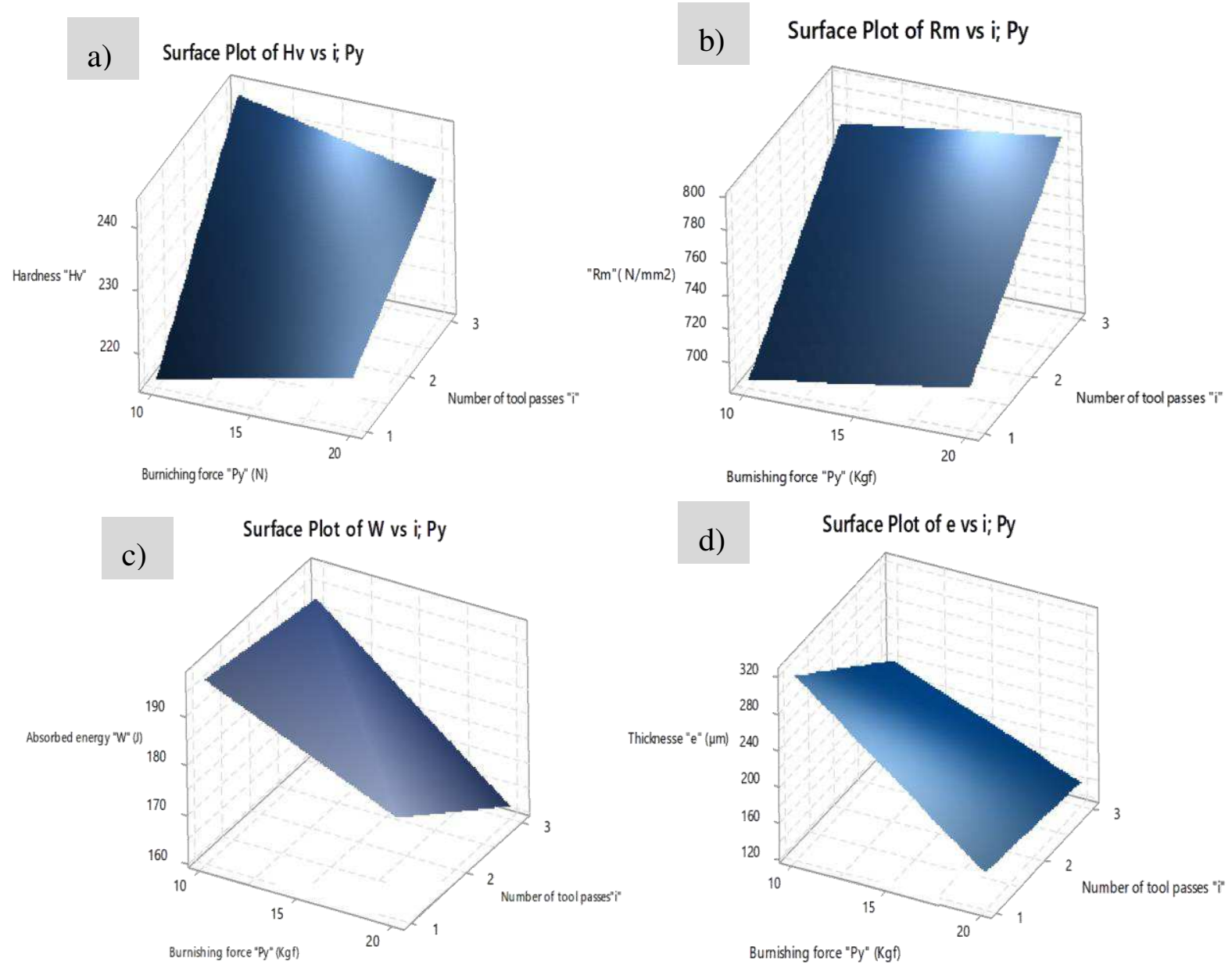

Figure 8. Influence of burnishing parameters on "Hv","Rm","W" and "e" 

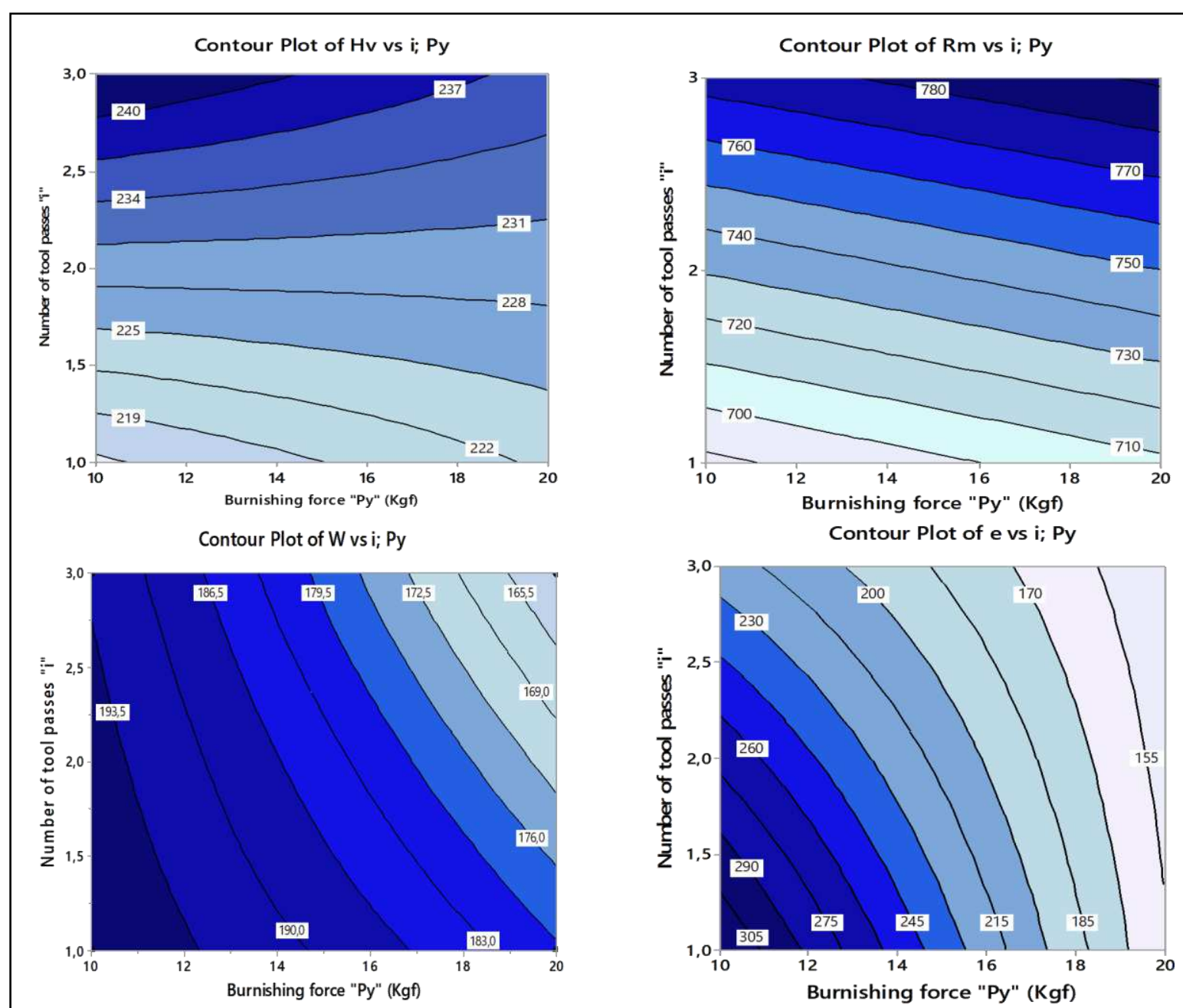

Figure 9. "Hv", "Rm", "W" and "e" contours in burnishing force and number of tool passes

The curve with a higher slope indicates that the factor has a greater influence on the response. From where we can deduce that the number of passes "i" considerably affects the surface hardness "Hv", and the breaking strength "Rm" while the load "Py" a very moderate effect on "Rm" (fig 10a , 10b). Plots of fitted means for energy "W" (Fig 10c) and work hardened thickness "e" (Fig0) show a big difference in the amplitude of the effects where the burnishing force "Py" is distinguished more significantly, compared to the number of tool passes " $\mathrm{i}$ ". In addition, the interaction graphs (Fig 11) clearly indicate that the evolution of hardness "Hv" as a function of Py is governed by the number of tool passes (Fig. 11a), while for the rupture resistance "Rm" there is no visible interaction between the two input parameters (Py, i) (Fig. 11b). Moreover, there seems to be a visible interaction of the two parameters (Py, i) for the energy "W" and the hardened thickness "e" (Fig 11c, 11d) where the burnishing force "Py" being the factor the most dominant compared at number of tool passes "i". 


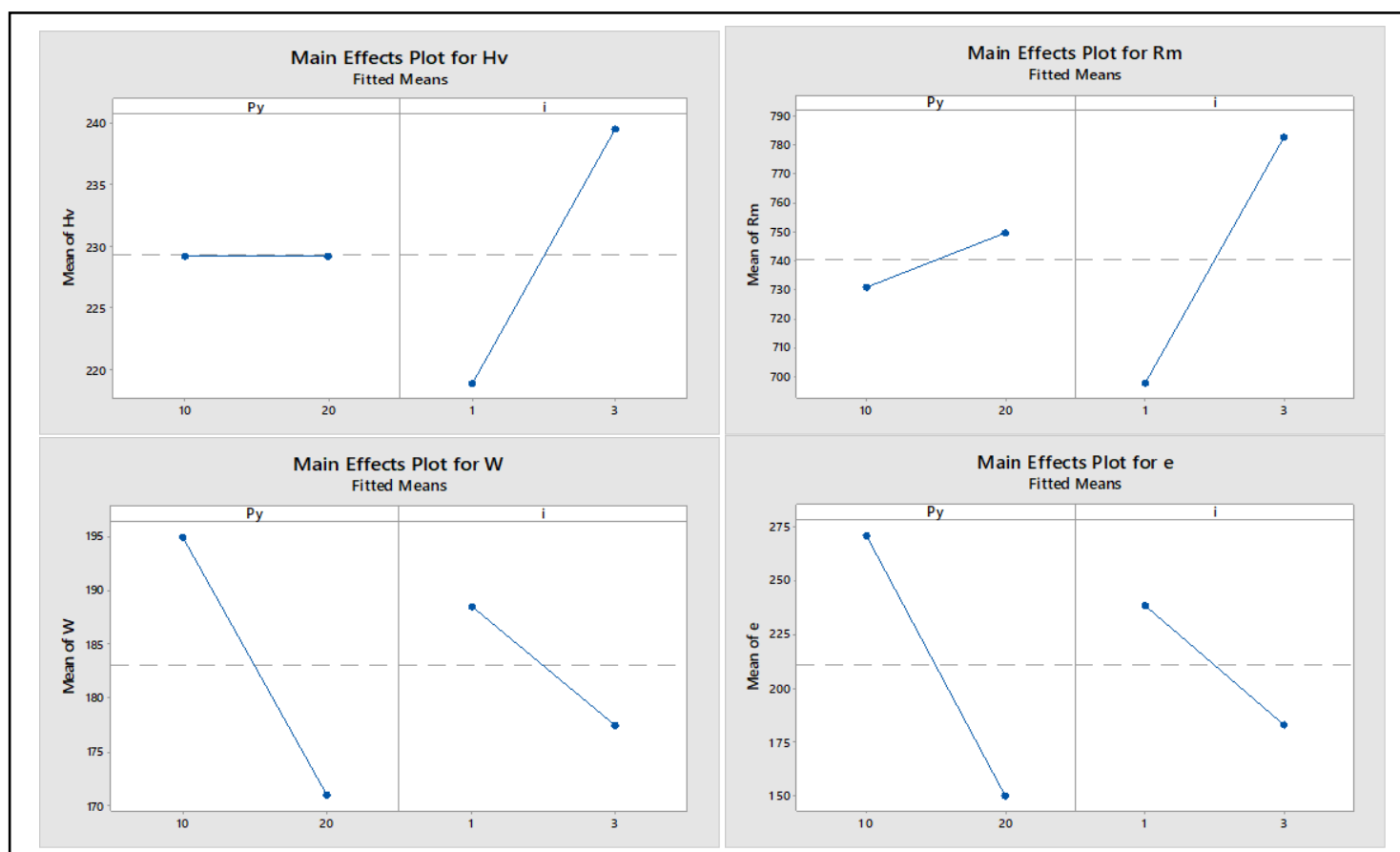

Figure 10 Main effects plot for : Hv, Rm, W and e

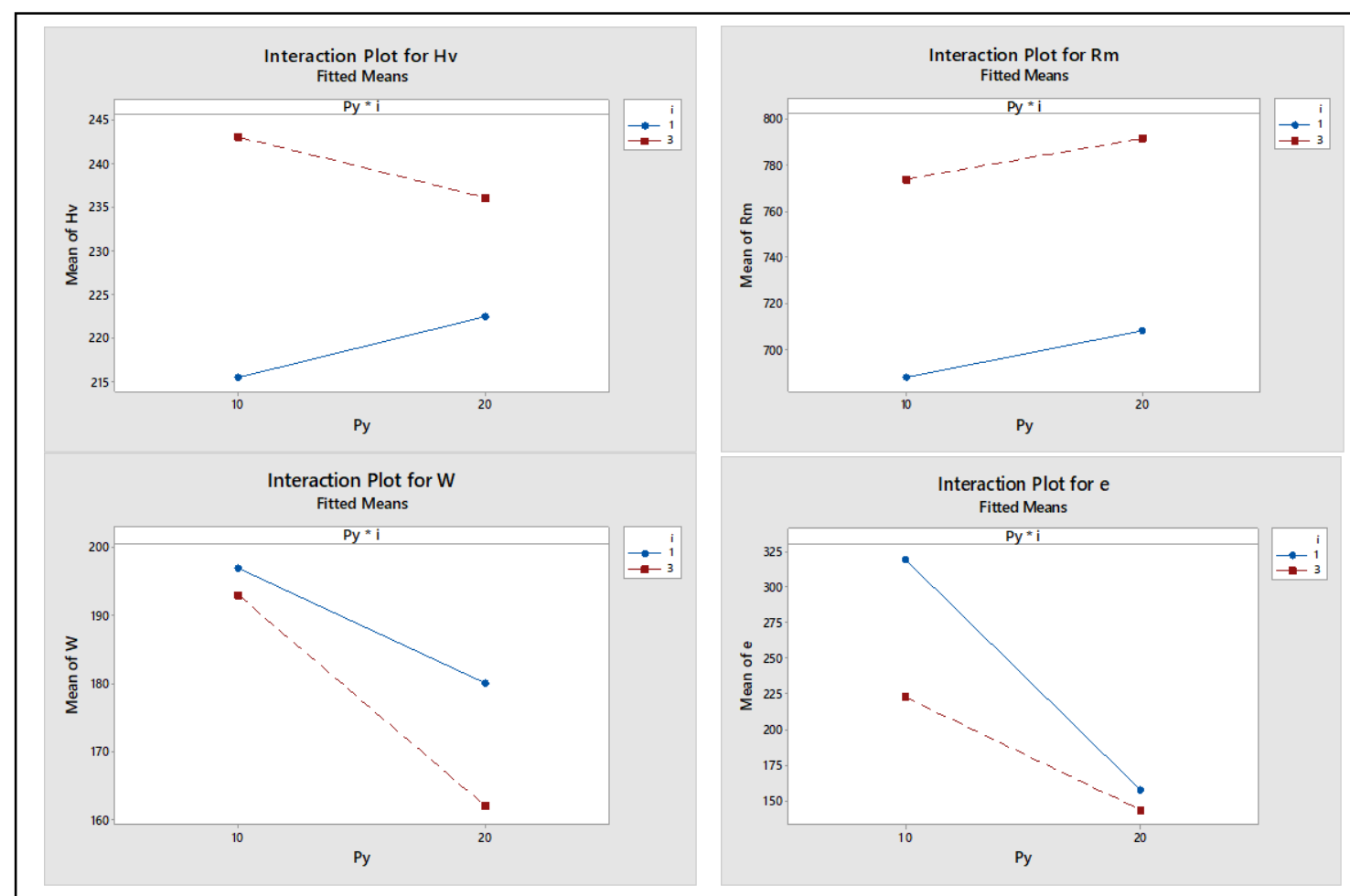

Figure 11 Interaction plot for : Hv, Rm, W and e 


\subsection{SEM observation and Fractographic analysis (Visual inspection)}

FIG. 12 shows different images acquired by means of an SEM microscope of the fracture facies of the impact test specimens which have undergone a superficial plastic deformation under different conditions. In the cases observed, it was confirmed that all samples broke at the sections where the stress concentration occurred due to the V-notch along which the section have decreased.

In any case, the rupture of the specimens was not manifested by a distinct separation into two or more parts. This means that burnishing cannot prevent stress concentration and has not altered the overall ductility of the material. Also for all ball burnishing conditions, examination of the ruptured surface reveals shattering of the matter in under layers and a clear surface.

Applying the burnishing parameters to their low levels $(\mathrm{Py}=10, \mathrm{i}=1 \mathrm{~N})$ (fig. 12a), the rupture facies shows the initiation of more than one crack and that the main crack $s$ 'is propagated in a zigzag, probably of the way an intergranular, following the grain joints. The cracked length is more or less important. By increasing the number of passes to 3 (fig. 12b), the material cracked in several places, especially at the beginning of the notch. However, the rupture was characterized by almost flat surfaces testifying to an almost fragile rupture.

By carrying out the burnishing with the high levels parameters ( $\mathrm{Py}=20$ and $\mathrm{i}=3$ ), there seems to be a large grain distortion due to the plastic deformation accompanying the burnishing process. In addition, we notice strong sliding of the material and the main crack has propagated in a direction inclined at about $45^{\circ}$ (Fig. 12c). The fissure is deeper and the length of the ruptured ligament is intense.

By maintaining the burnishing force at its highest level (Py = 20Kgf) with a single pass of tool, rupture occurs in a mixed mode. First a surface shear marked by the inclination of the main crack which then straightens out in a straight line by the effect of plane deformation where a cleavage of the material occurs (fig.12d). The ligament ruptured in this condition appears to be the shortest. 
a) $\mathrm{BB}\left(\mathrm{P}_{\mathrm{y}}=10 \mathrm{Kgf}, \mathrm{i}=1\right)$

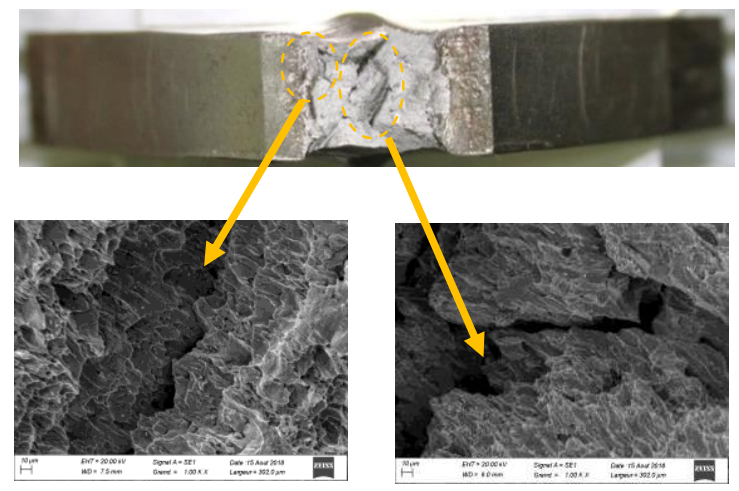

c) $B B\left(P_{y}=20 K g f, i=3\right)$

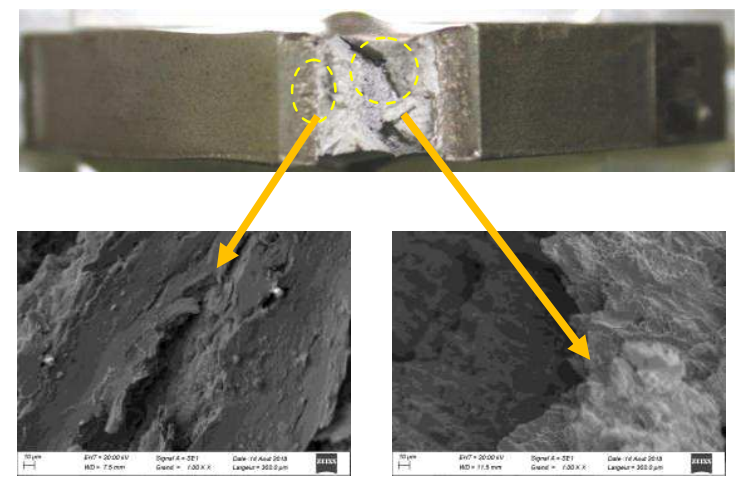

b) $\mathrm{BB}\left(\mathrm{P}_{\mathbf{y}}=10 \mathrm{Kgf}, \mathrm{i}=3\right)$

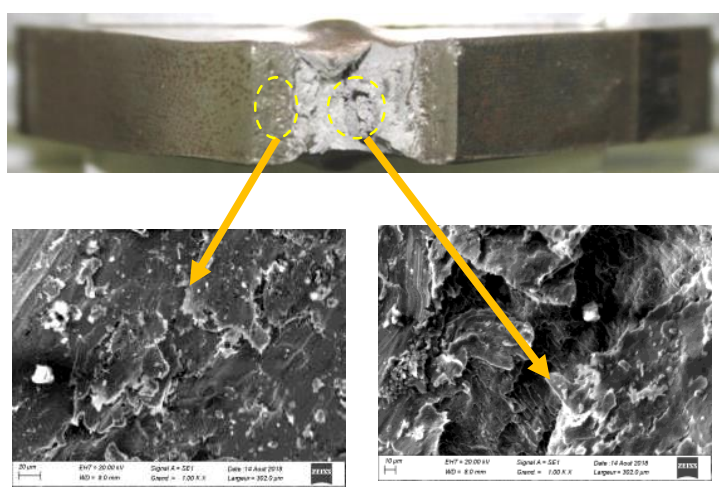

d) $B B\left(P_{y}=20 K g f i=1\right)$

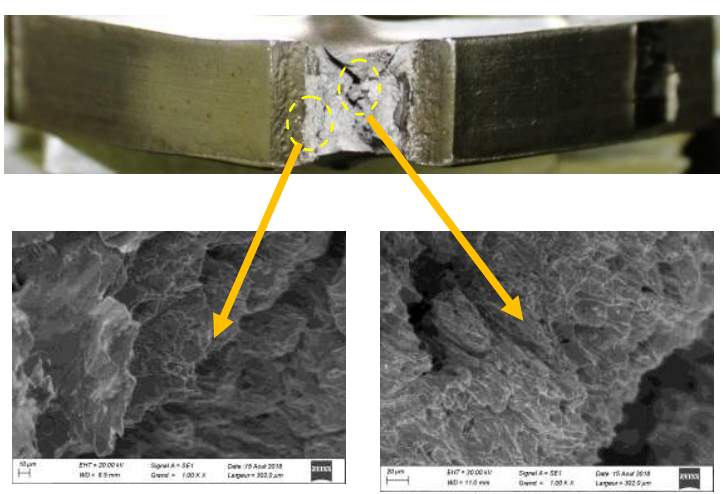

Figure12. Fracture facies by impact test of S355JR steel under various burnishing conditions.

\section{Conclusion}

The ball burnishing process has been successfully performed on S355JR steel surfaces to improve mechanical properties $(\mathrm{Hv}, \mathrm{Rm})$ and energy absorbed during impact test as well as work hardened thickness. The response surface methodology allowed establishes a correlation between the treatment parameters in this case (burnishing force and number of passes) and the responses studied. Founded on the analysis of experimental results, the following conclusions can be outlined:

- The low levels favor the best impact tenacity which gains $26.28 \%$ although under these conditions the layer affected by the BB is the more deep $(e=319.52 \mu \mathrm{m})$. The combination of $10 \mathrm{Kgf}$ force at 3 passes best allowed to increase the surface hardness by $30.46 \%$.

- The high levels of "Py" and "i" harden the superficial layers by increasing their "Rm" by $30.8 \%$ without altering the material ductility and favor an increase in tenacity of only $3.6 \%$. The hardened area is the shallowest $(143.35 \mathrm{~J})$. The best resilience results were obtained with the lowest force and number of tool passes.

- On the other hand, quenching and tempering improve the strength "Rm" by $183 \%$ and $119 \%$ respectively, while the burnishing effect was limited to a rate of increase of this property of $28 \%$ compared to machining. 
- The applied force "Py" and the number of tool passes "i" are statistically influential in the evolution of output responses considered in this study with a confidence level of 95\%. There is an interaction between them for all output responses. The number of tool passes is the most significant on the hardness "Hv" and the rupture strength "Rm" of superficial layers. The force is more significant for resilience and penetration depth.

- The impact fracture facies reveal that under all conditions, burnishing causes bursts in the material sub-layers. By conducting the BB with the parameters at high levels, the material is exposed great grain distortion and strong slip. The increased number of tool passes " $\mathrm{i}$ " causes additional cracking when combined with low force. By increasing the force to $20 \mathrm{kgf}$ we promote a mixed rupture under the impact effect.

\section{Acknowledgment}

I would like to thank the entire of metallography laboratory team of at URASM/CRTI.

Funding: "This research received no external funding"

Conflicts of Interest: "The authors declare no conflict of interest."

Author Contributions: Investigation, Laouar Lakhdar, Hazem Tarek and Taleb Ahlem; Methodology, Hamadache Hamid; Supervision, Djemili Kamila.

\section{References}

1. Saldaña-Robles A and al, (2018) Influence of ball-burnishing on roughness, hardness and corrosion resistance of AISI 1045 steel. Surface \& Coatings Technology: 339191-8

2. Andres AG-Getal, (2017) Ball-burnishing effect on deep residual stress on AISI 1038 and AA2017-T4. Mater Manuf Processes ; https://doi.org/http10.1080/10426914.2017. $\underline{1317351}$

3. M. Bourebia and al (2019) Effect of heat treatment on surface hardness and tribological behavior of XC38 steel — approach by the experiments plans. Mater. Res. Express volume $6: 076568$.

4. D. F. Silva-Avarez and al, 2020 Improving the surface integrity of the CoCrMo alloy by the Ball burnishing technique. Journal of Materials Research and Technology volume 9, 4: 7592-7601.

5. Milton Coba Salcedo (2018) Study of the Influence of the Honing Process by Plastic Deformation on the Turning of AISI 1045 Steel. Contemporary Engineering Sciences volume 11(79): 3939-3947, DOI: 10.12988/ces.2018.88424

6. Tobola D and al (2020) Surface Treatment for Improving Selected Physical and Functional Properties of Tools and Machine Parts-A Review. J. Appl. Mater. Eng. ; volume 60 (1): 23-36, DOI: 10.35995/jame60010003.

7. Vashishtha $\mathrm{N}$ and al, (2018) Effect of heat treatment on friction and abrasive wear behaviour of WC-12Co and $\mathrm{Cr} 3 \mathrm{C} 2-25 \mathrm{NiCr}$ coatings Tribol. Int:118381-99

8. Krishna $\mathrm{M}$ and al, (2018) Microstructure, hardness and wear rate of heat treated Titanium surface alloyed AISI304 stainless steel. Materials Today Proceedings: 57571-6.

9. J.T. Maximov et al, Slide burnishing — review and prospects.

10. A.A. García-Granada and al (2017) Ball-burnishing effect on deep residual stress on AISI 1038 and AA2017-T4]. Materials and Manufacturing Processes Volume 32,11 https://doi.org/10.1080/10426914.2017.1317351

11. Mezlini and al, (2014) Effect of a combined machining/burnishing tool on the roughness and mechanical properties. Lubrication Science 26(3) DOI: 10.1002/ls.1239

12. D. Tobola and al, (2015) Structure and Properties of Burnished and Nitrided AISI D2 Tool Steel. Materials Science volume 21(4) DOI: 10.5755/j01.ms.21.4.7224 
13. D. Tobola and al, (2020) TEM analysis of surface layer of Ti-6Al-4V ELI Alloy after slide burnishing and low temperature gas nitriding. Applied Surface Science Volume 515 (15), 145942.

14. L. Wagner, Combining MST with Heat treatment. Advanced materials and processes $7 / 94$

15. Avilès and al. (2013) Influence of low-plasticity ball burnishing on the high-cycle fatigue strength of medium carbon AISI 10 45, International Journal of Fatigue Volume 55 : 230244

16. A. Rodriguez, (2012) Surface improvement of shafts by the deep ball-burnishing technique. Surface and Coatings Technology volume 206, 11:2817-2824

17. Pascale Balland and al (2013) Mechanics of the burnishing process, Precision Engineering,; volume 37, ( 1):129-134.

18. Deepak Mahajan, Ravindra Tajane (2013) A Review on Ball Burnishing Process, International Journal of Scientific and Research Publications volume3, (4).

19. Rababa S. K., Al-Mahasne M. M. (2011) Effect of Roller Burnishing on the Mechanical Behavior and Surface Quality of O1 Alloy Steel. Research Journal of Applied Sciences Engineering and Technology volume3: 227-233.

20. S. Dzionk, (2019) Surface Texture Analysis of Hardened Shafts after Ceramic Ball Burnishing, Materials volume12, 204; doi:10.3390/ma12020204.

21. F.Gharbi, S. Sghaier, K. J. Al Fadhalah, and T. Benameur, (2011) Effect of ball burnishing process on the surface quality and microstructure properties of AISI 1010 steel plates, JMEPEG volume 20 (6).

22. H. Luo and al, (2006) Study of the mechanism of the burnishing process with cylindrical polycrystalline diamond tools, Journal of Materials Processing Technology volume 180, (1-3): 9-16.

23. Gomez-Gras G, Travieso-Rodríguez JA, González-Rojas HA, Nápoles-Alberro A, Carrillo F, Dessein G. (2014) Study of a ball-burnishing vibration-assisted process. Inst Mech Eng B J Eng Manuf volume 229(1):172-7.

24. Milton F. Coba Salcedo and al, (2018) Design of Ball Burnishing Tool with Interchangeable Tip. Contemporary Engineering Sciences,; volume 11(79): 3921-3927

25. Berat Baris Buldum, (2018) Investigation of surface roughness and microhardness in ball burnishing process of AZ31b magnesium alloy, Selcuk Univ. J. Eng. Sci. Tech. volume 6, (1): 152-161,

26. M. Salahshour, (2011) Surface integrity of biodegradable Magnesium-Calcium orthopedic implant by burnishing, Journal of the Mechanical Behavior of Biomedical Materials; volume 4, (8) pp 1888-1904.

27. Lukasz Janczewski and al (2016) Effects of ball burnishing on surface properties of low density polyethylene, January Tribology International, volume 93: 36-42 DOI: 10.1016/j.triboint.2015.09.006

28. Babic M, and al (2017) Investigation of ball burnishing processing on mechanical characteristics of wooden elements. Proc IMechE Part C: J Mech Eng Sci volume 231(1):120-127.

29. Gökhan BAŞAR, Funda Kahraman (2018) prediction of surface hardness in a burnishing process using Taguchi method, fuzzy logic model and regression analysis, sigma j eng \& nat sci, ; volume 36 (4): 1281-1293.

30. M. Kowalik and al (2019) Experimental Assessment of the Depth of the Deformed Layer in the Roller Burnishing Process, MATEC Web of Conferences, volume 290: 03008 DOI: $\underline{10.1051 / \mathrm{matec} \text { onf } / 201929003008}$ 
31. Hamadache $\mathrm{H}$ and al , (2014) Improvement of surface conditions of $36 \mathrm{Cr}$ NiMo 6 steel by ball burnishing process. Journal of Mechanical Science and Technology volume 28 (4): 1491 1498.

32. V. Ferencsik, G. Varga, (2019) Examination of the Change in Surface micro-hardness of Burnished Al Alloy components, International Multidisciplinary Scientific Conference, DOI: $10.26649 /$ musci.2019.087

33. J.A. Travieso-Rodríguez, (2019) Hardening effect and fatigue behavior enhancement through ball burnishing on AISI 1038, Journal of Materials Research and Technology ; 8, (6):5639-5646.

34. Bounouara and al, (2018) Investigation on the effect of ball burnishing on fracture toughness in spiral API X70 pipeline steel, Int J Adv Manuf Technol, volume 94: 45434551

35. J.T. Maximov and al. (2019) Effect of cyclic hardening on fatigue performance of slide burnished components made of low-alloy medium carbon steel, Fatigue and fracture of engineering materials and structure. https://doi.org/10.1111/ffe.13001

36. Jordi Llumà and al, (2020) Mechanical Strengt hening in S235JR Steel Sheets through Vibration-Assisted Ball Burnishing, Metals, volume 10, 1010: 1-13.

37. Tourab Mohamed and al, (2017) Effect of Roller Burnishing Parameters on Roughness Surface and Hardness of Unalloyed S 355 J0 Steel by Using Response Surface Methodology, Manufacturing Technology, volume 17 (4) : ISSN 1213-2489.

38. Deepak Mahajan, Ravindra Tajane, (2013) The Optimization of Surface Roughness of Al 6061 using Taguchi Method in Ball Burnishing Process, International Journal of Scientific and Research Publications, volume 3 (10).

39. H. Basak and al (2019) Experimental Research and ANN Modeling on the Impact of the Ball Burnishing Process on the Mechanical Properties of 5083 Al-Mg Material Sheets through Vibration-Assisted Ball Burnishing, Kovove Materialy, volume 57(1): 61-74.

40. Mounira Bourebia and al (2019) Study of the effect of burnishing on superficial hardness and hardening of S355JR steel using experimental planning, Energy Procedia, volume 157: $1-1568$.

41. G Basar et F. Kahraman, (2018) Prediction of Surf Hardness in a Burnish Process using Taguchi Method, Fuzzy Logic and Regression Analysis, Sigma J Eng and Nat Sci, volume36 (4): 1281-1293.

42. Ishfaq and al. (2020) Modelling the Mechanical Attributes (Roughness, Strength, and Hardness of Al-alloy A356 during Sand Casting, Materials (Basel), volume 13(3): 598. doi: $10.3390 / \mathrm{ma1} 3030598$

43. Goupy J Experiment Plans for the Response Surface (Paris: Dunod), 1999 
Figures

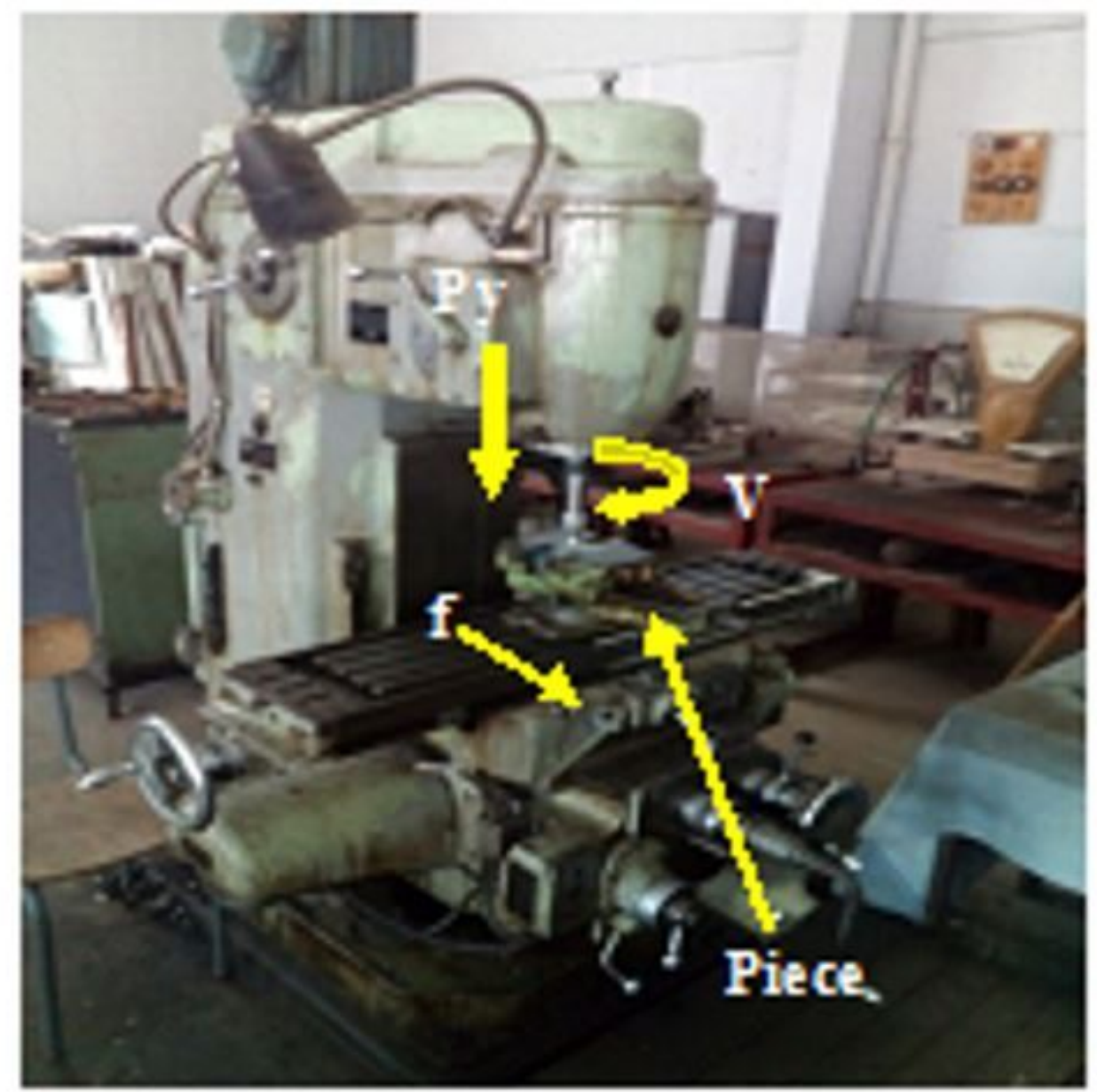

Figure 1

Burnishing device mounted on a milling machine 


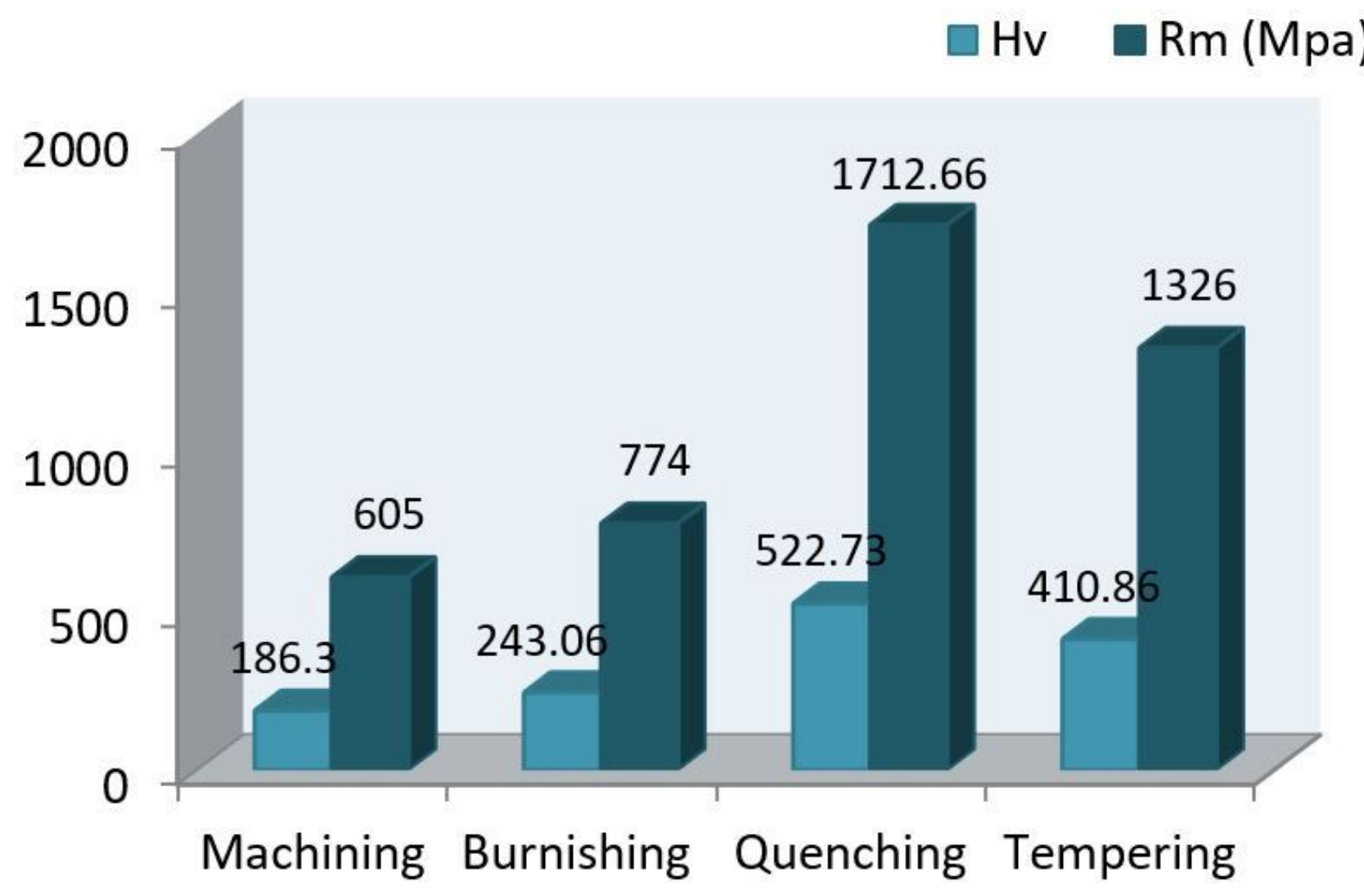

Figure 2

Effects of heat treatments on the properties of S355JR steel.

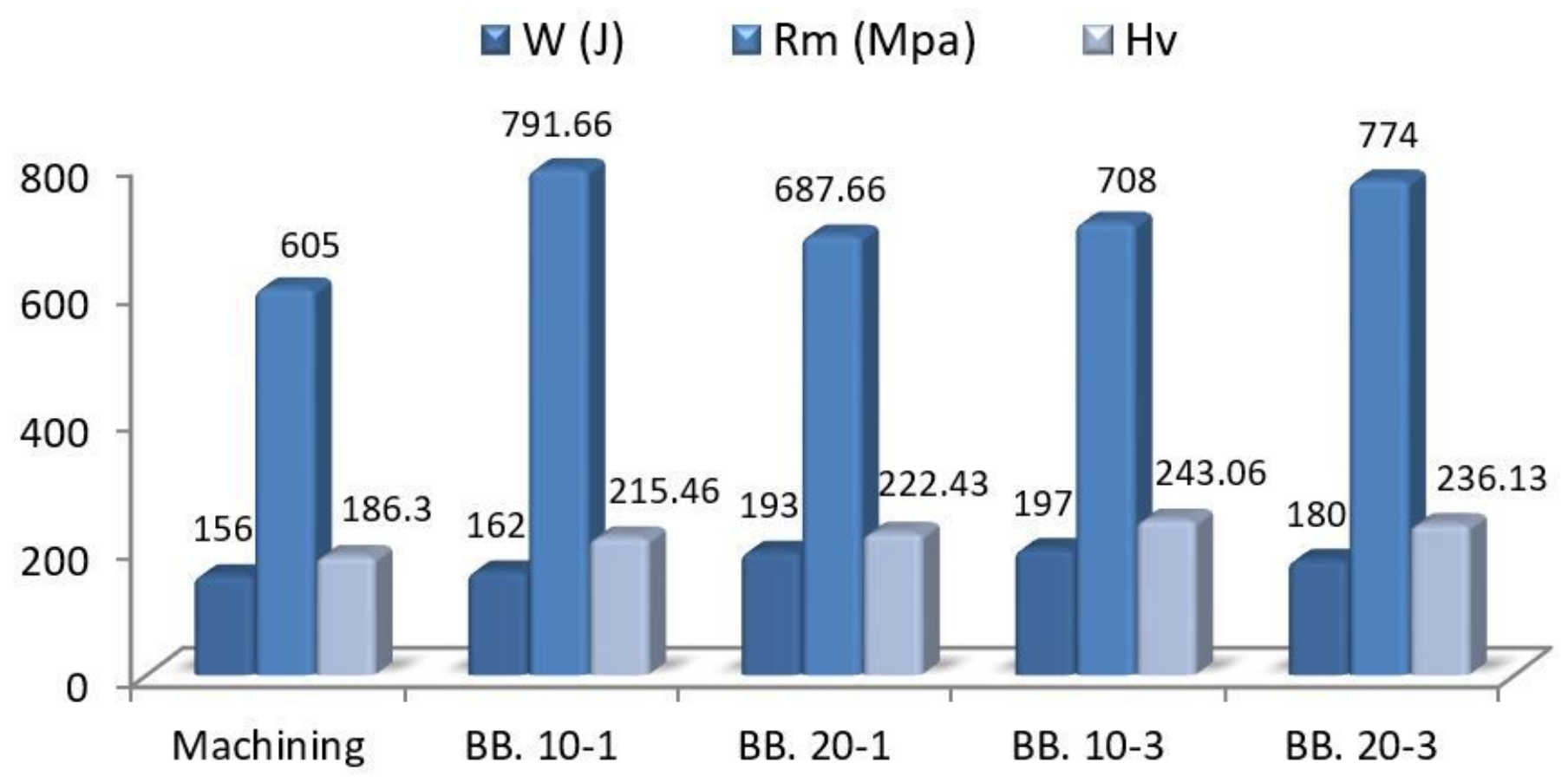

Figure 3 
Burnishing effects on the properties of S355JR steel.

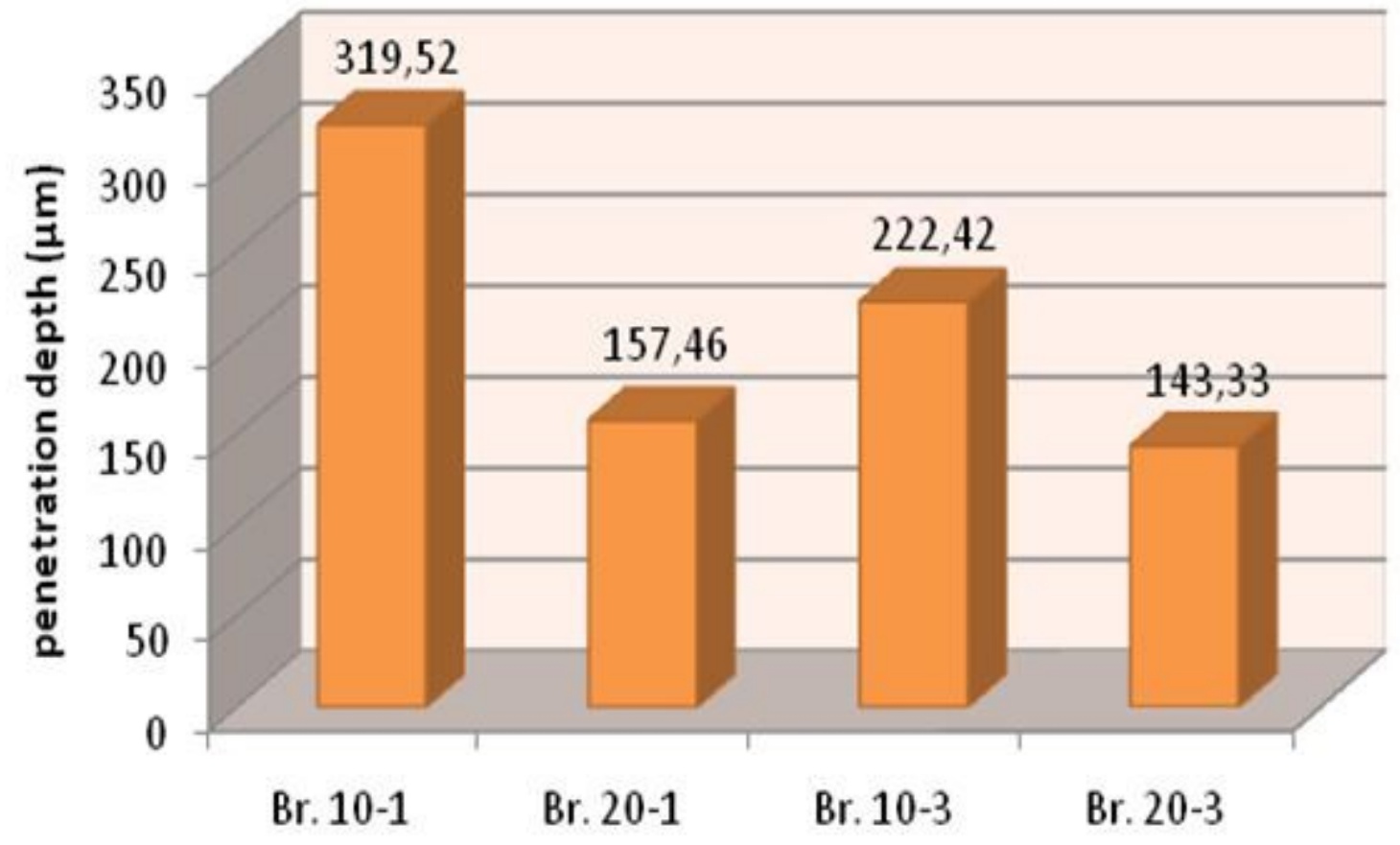

Figure 4

Effects of burnishing parameters on the penetration depth (e).

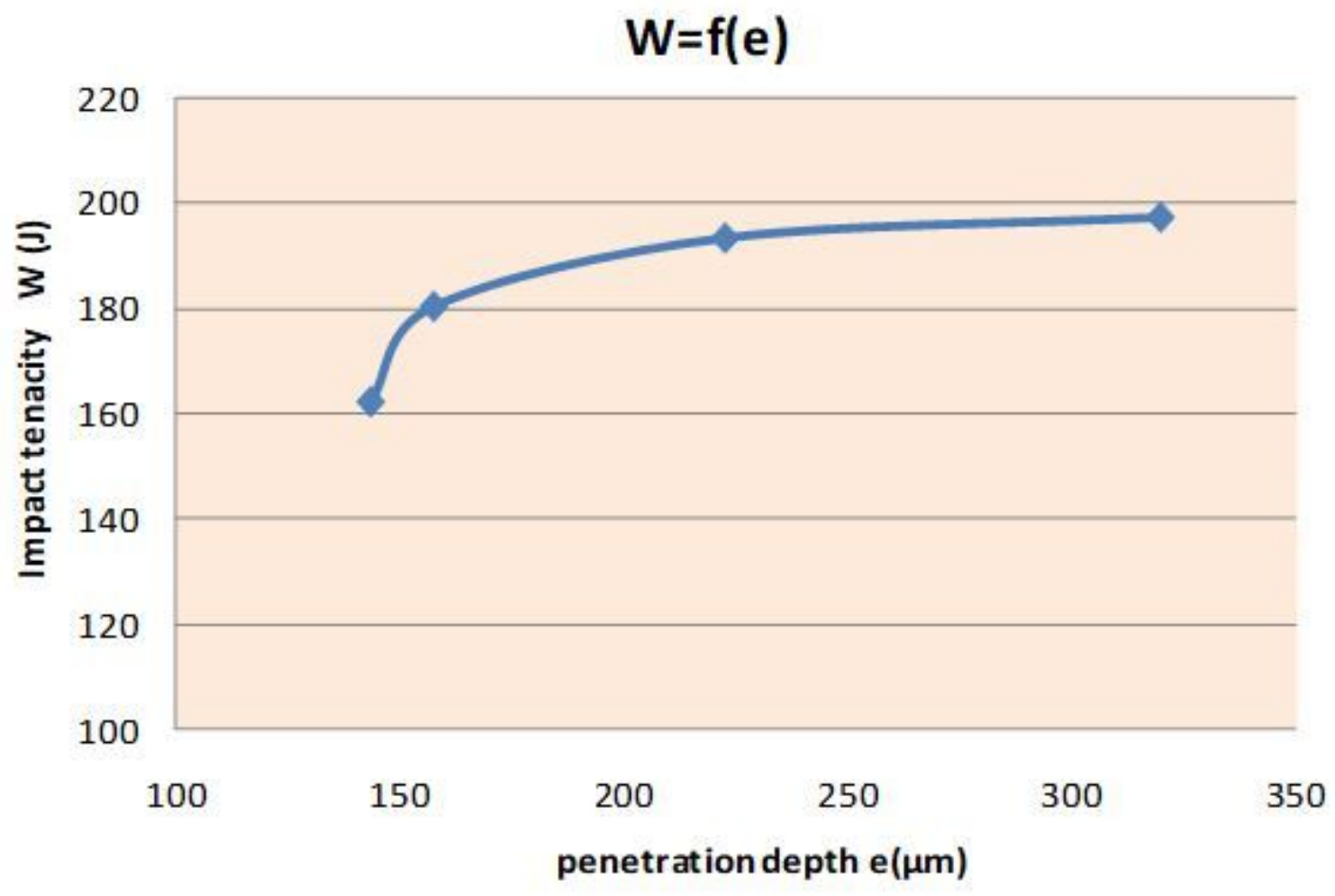

Figure 5 
Evolution of the energy absorbed (W) as a function of penetration depth

a) $\mathrm{BB} 10 \mathrm{Kgf}-1 \mathrm{p}$
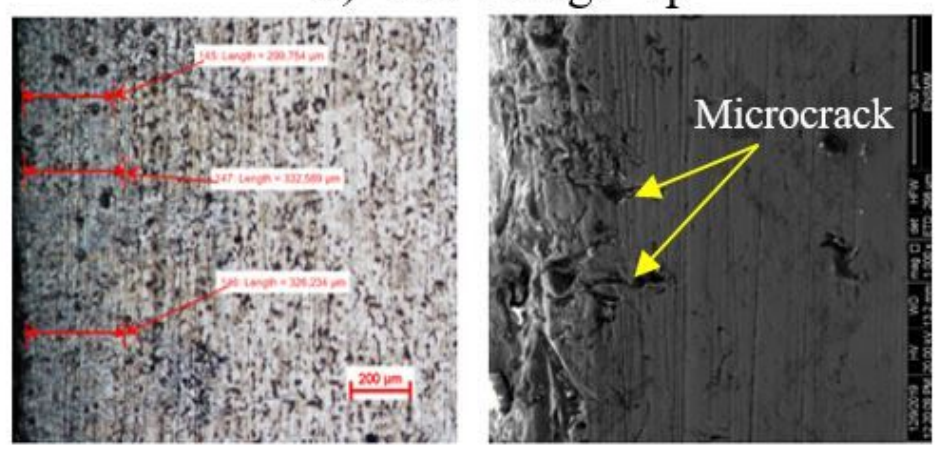

c) BB $10 \mathrm{Kgf}-3 \mathrm{p}$
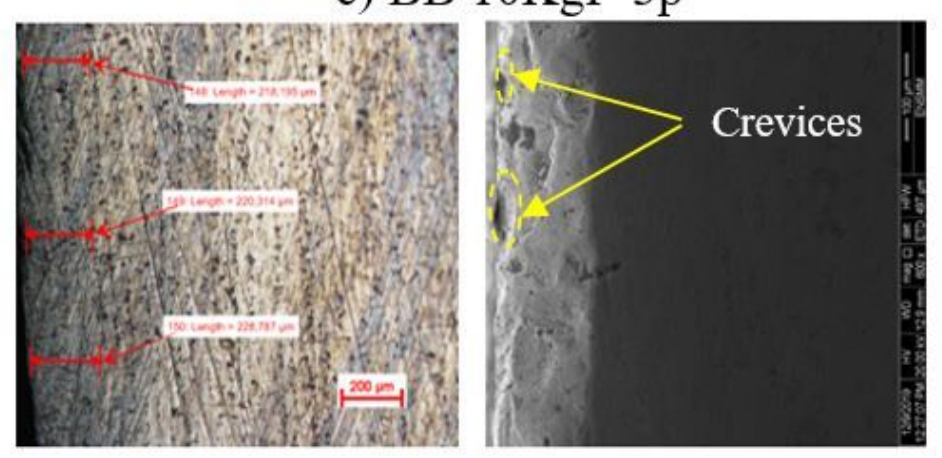

b) BB 20Kgf- $1 p$
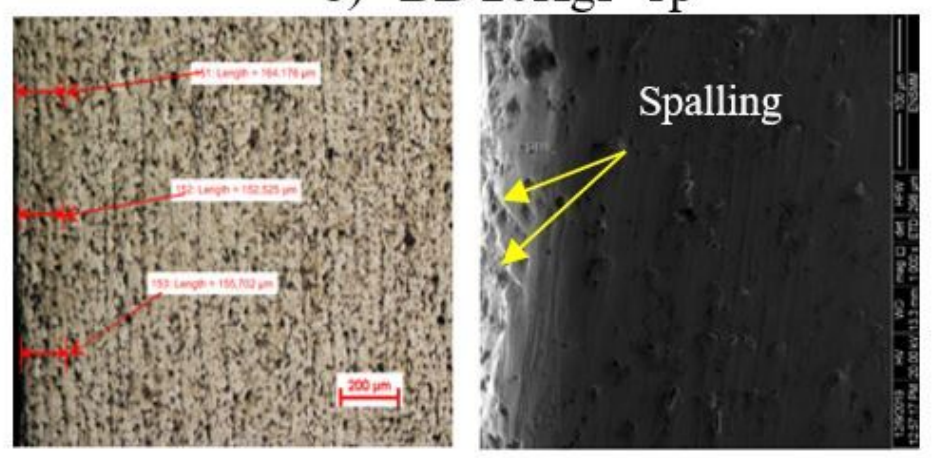

d) BB $20 \mathrm{Kgf}-3 \mathrm{p}$
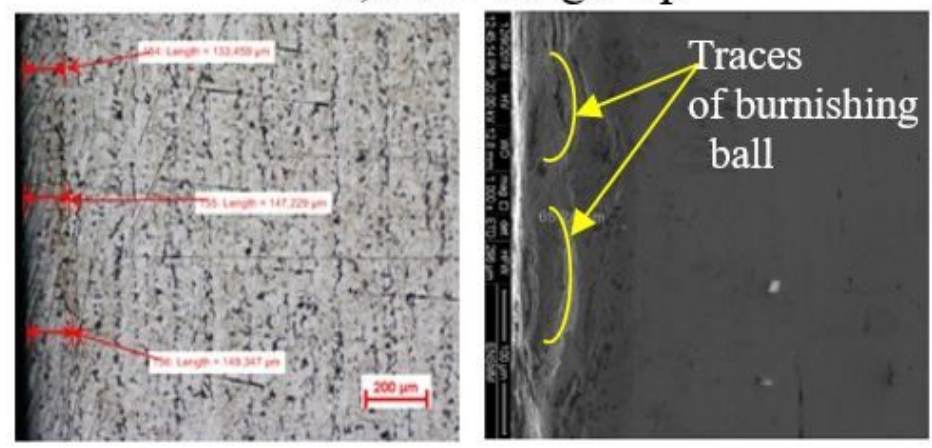

\section{Figure 6}

Micrograph of hardened superficial layer by burnishing 


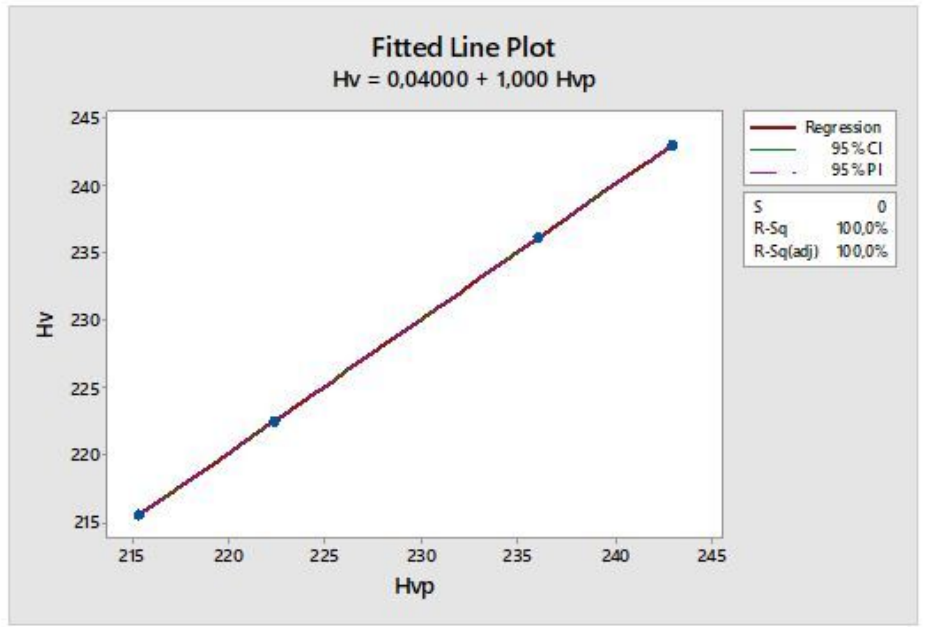

Fitted Line Plot $W=0,000000+1,000 W p$

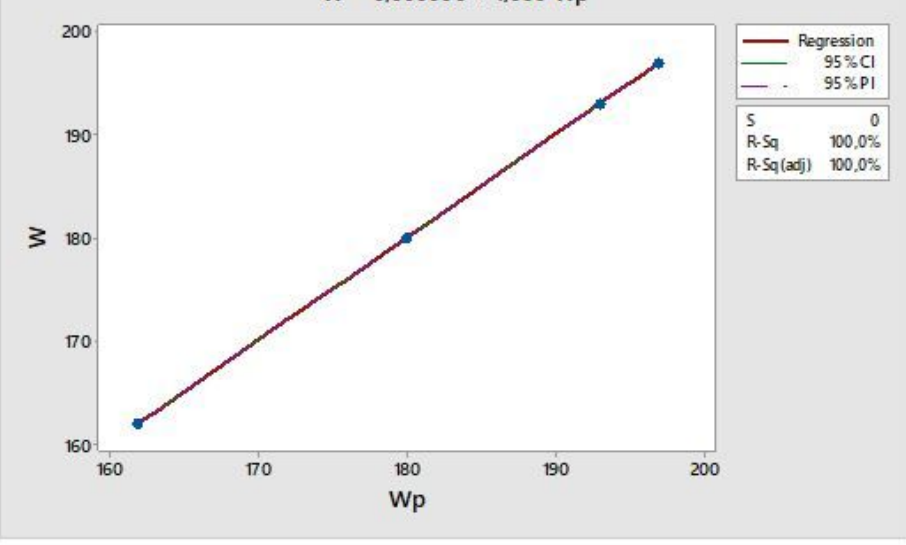

Fitted Line Plot

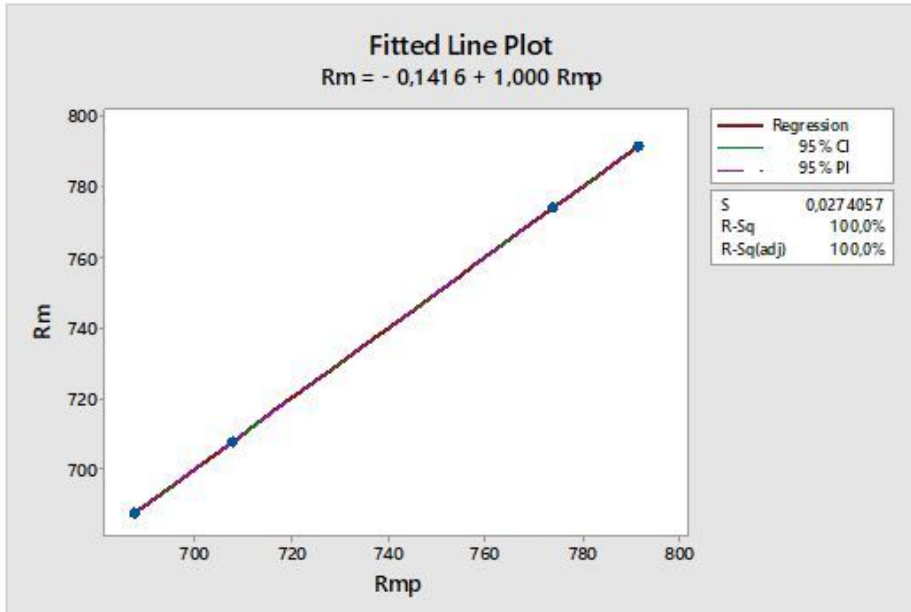

Fitted Line Plot

$e=-0,1317+1,000 \mathrm{ep}$

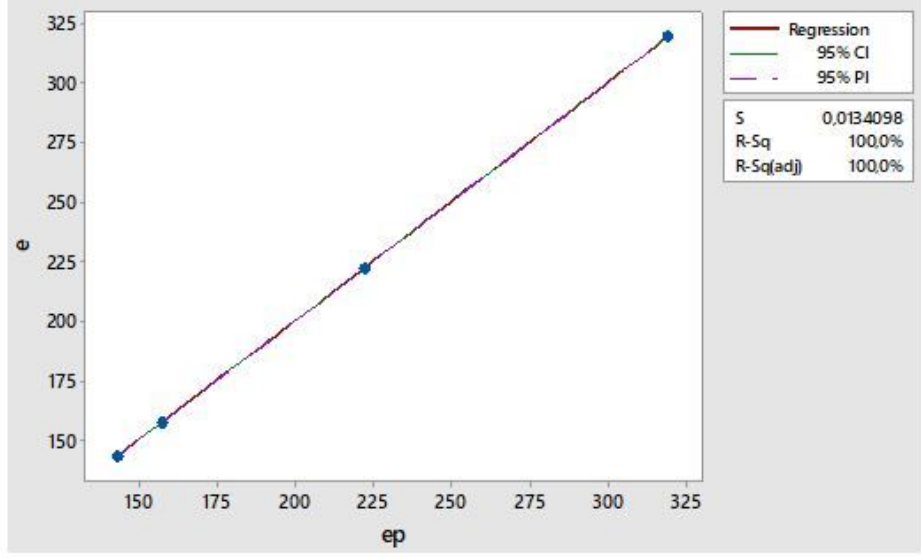

Figure 7

Predicted values and experimental values for a) $\mathrm{Hv}, \mathrm{b}$ ) $\mathrm{Rm}, \mathrm{c}$ ) W and d) e 

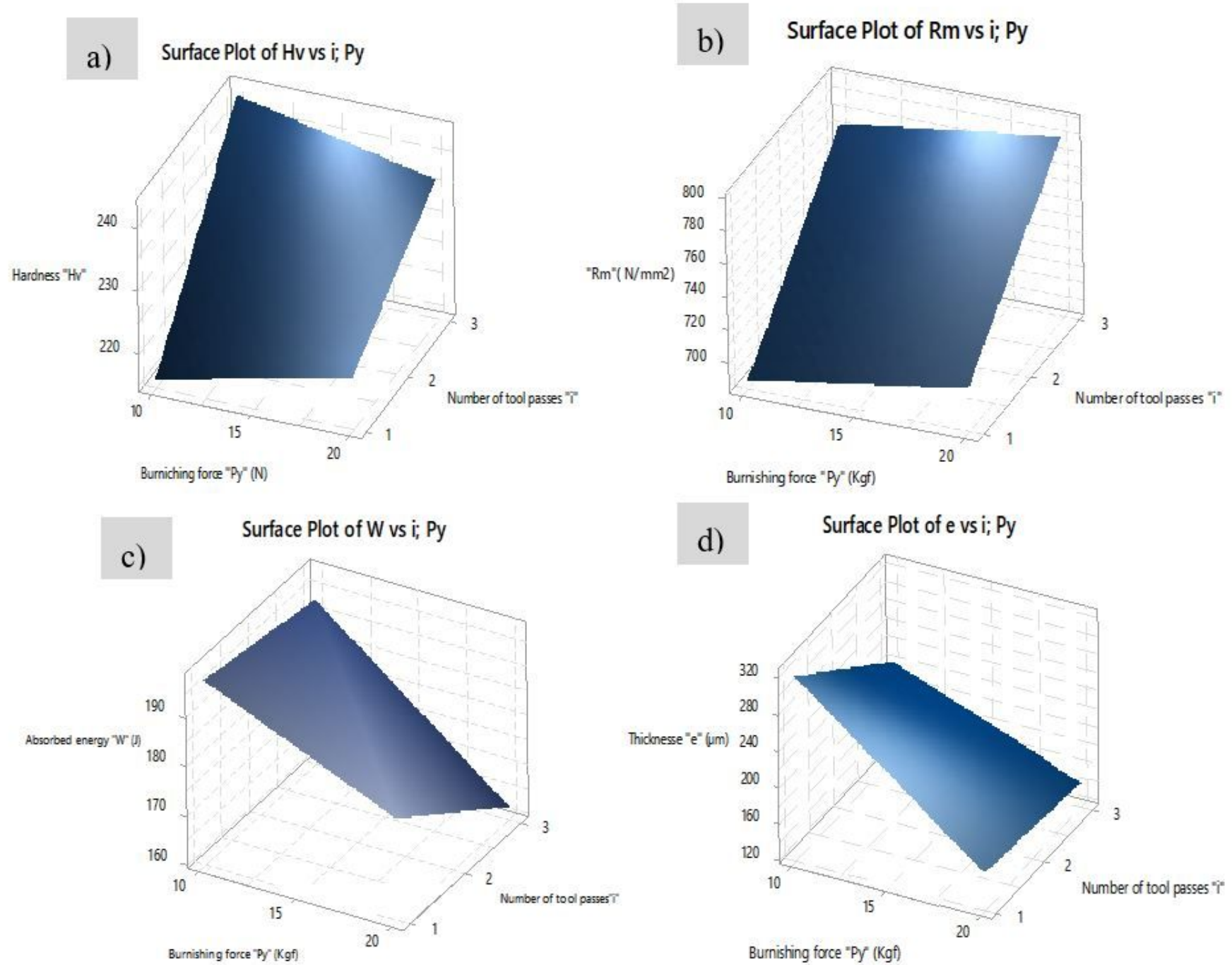

\section{Figure 8}

Influence of burnishing parameters on "Hv","Rm","W" and "e" 


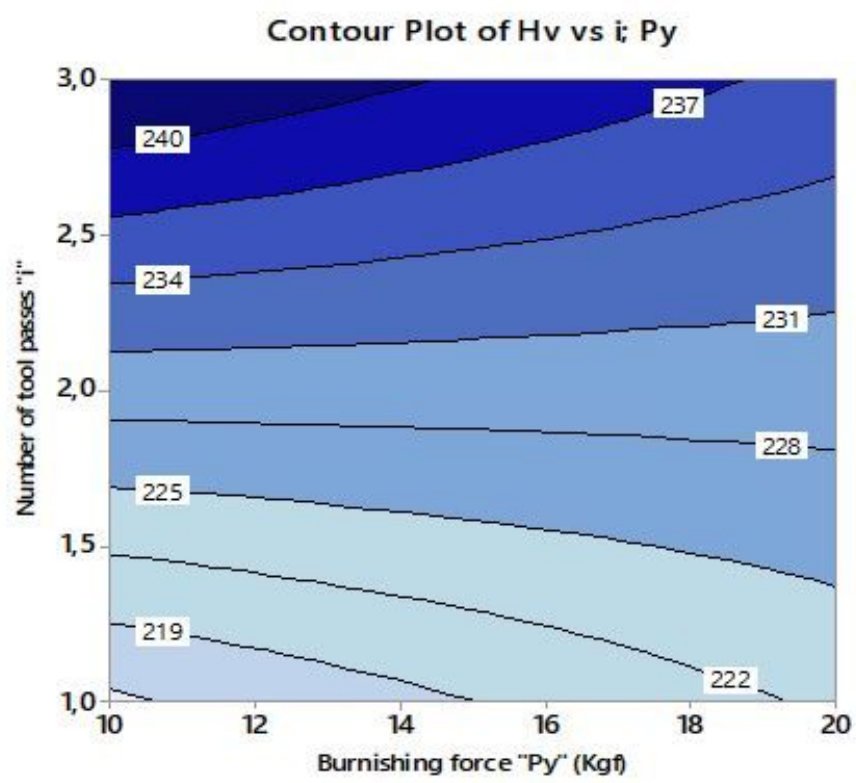

Contour Plot of Wvs i; Py
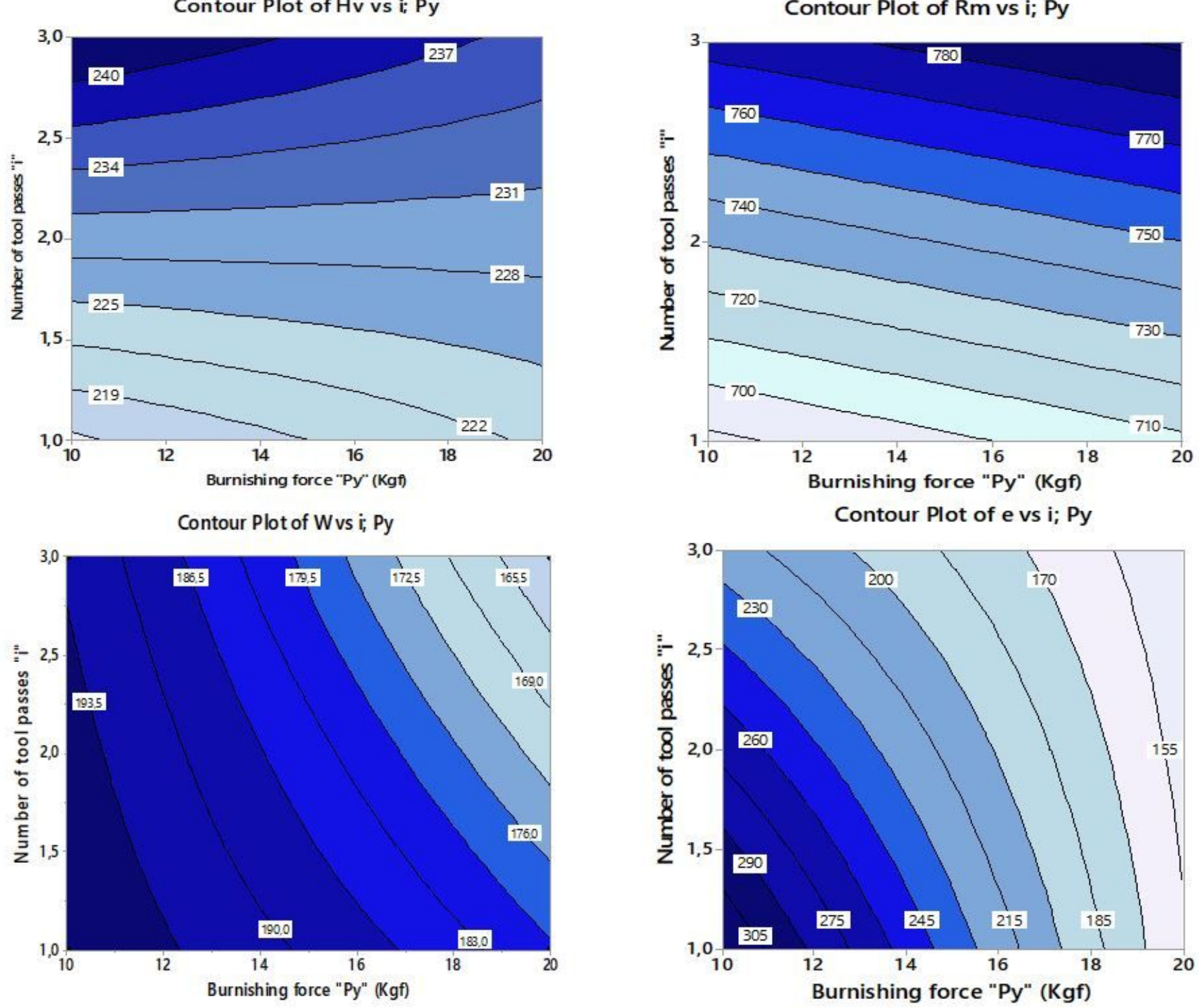

Figure 9

"Hv", "Rm", "W" and "e" contours in burnishing force and number of tool passes 

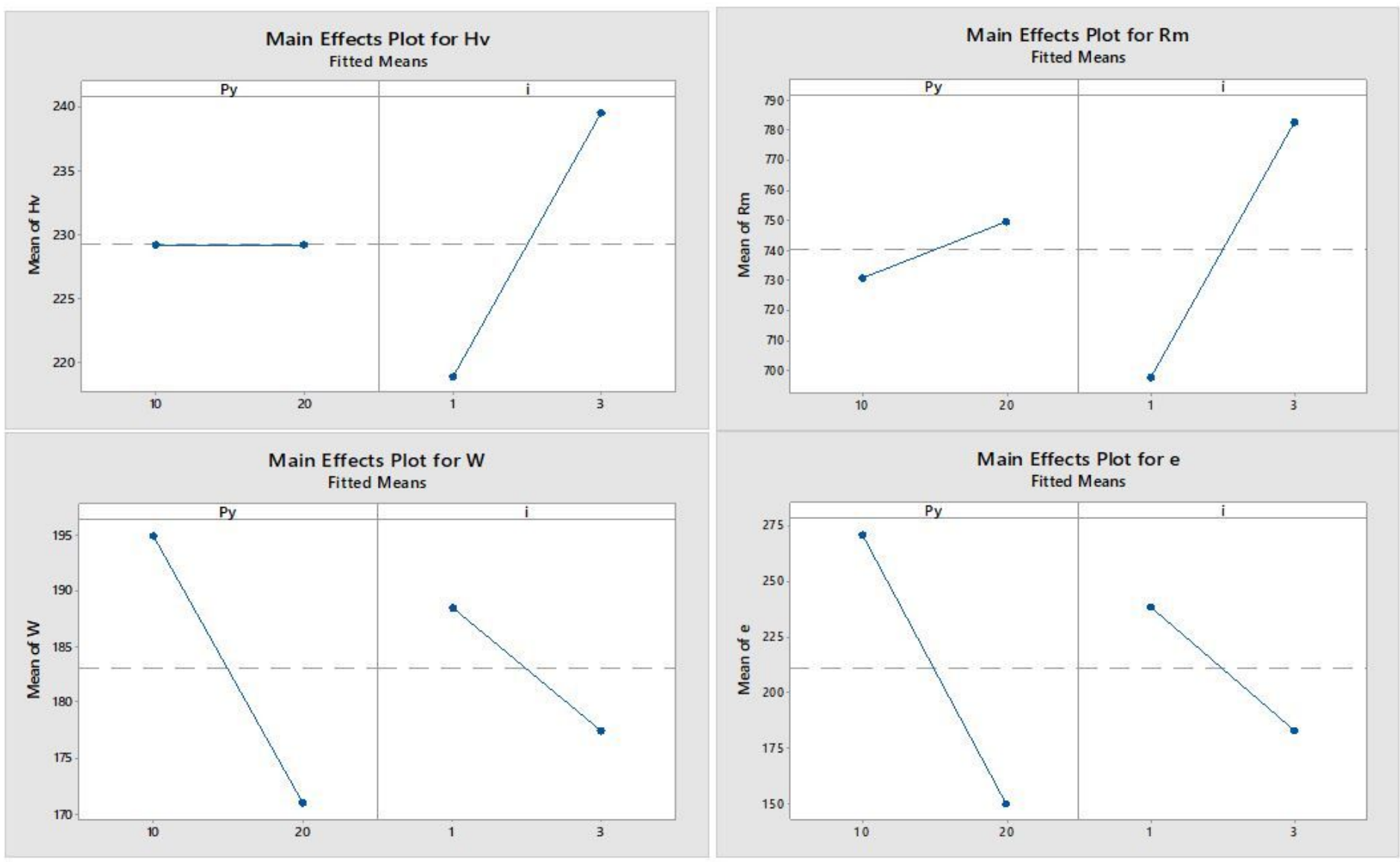

\section{Figure 10}

Main effects plot for: $\mathrm{Hv}, \mathrm{Rm}, \mathrm{W}$ and e 

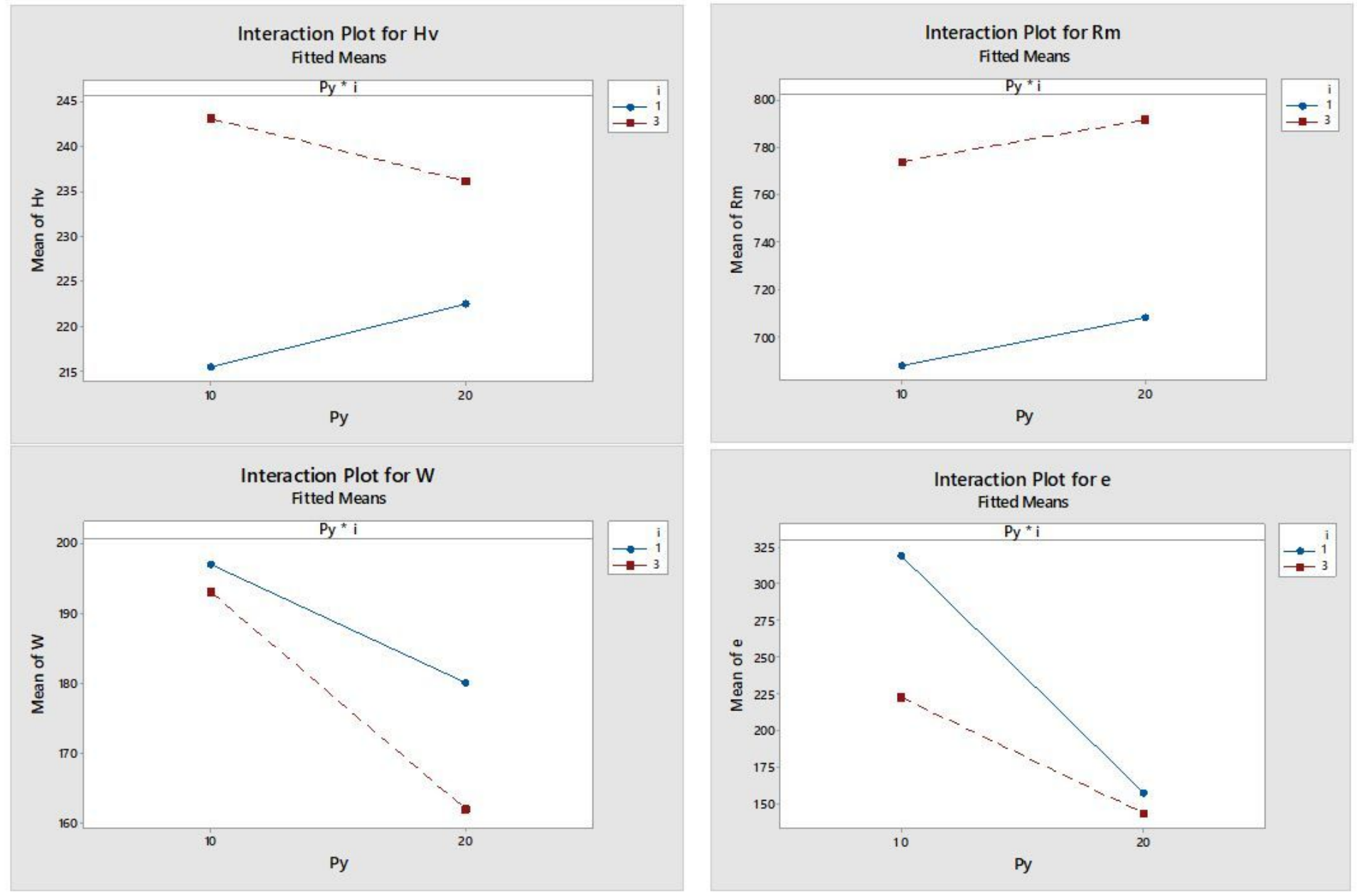

Figure 11

Interaction plot for: $\mathrm{Hv}, \mathrm{Rm}, \mathrm{W}$ and $\mathrm{e}$ 

a) $B B\left(P_{y}=10 K g f, i=1\right)$

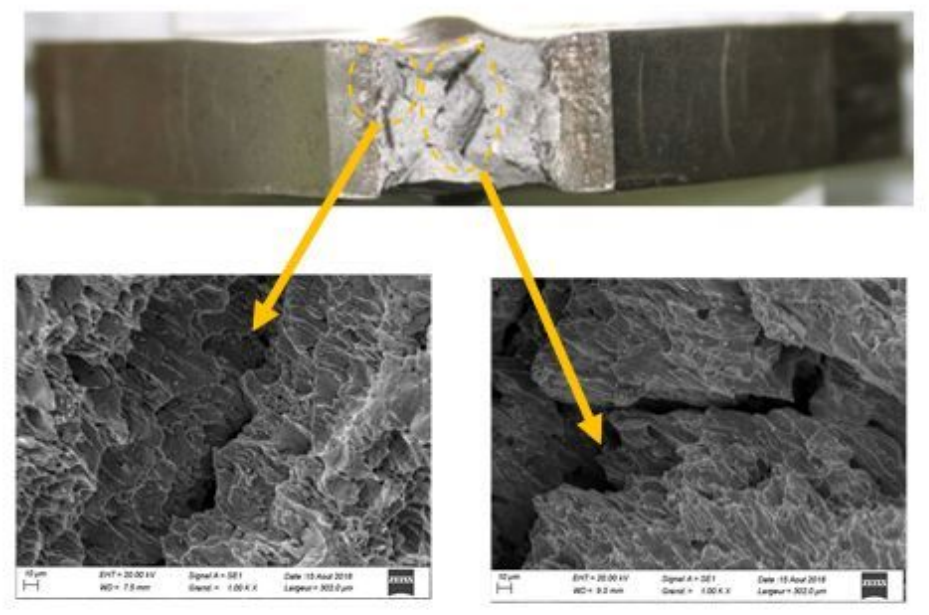

c) $\mathrm{BB}\left(\mathrm{P}_{\mathrm{y}}=20 \mathrm{Kgf}, \mathrm{i}=3\right)$

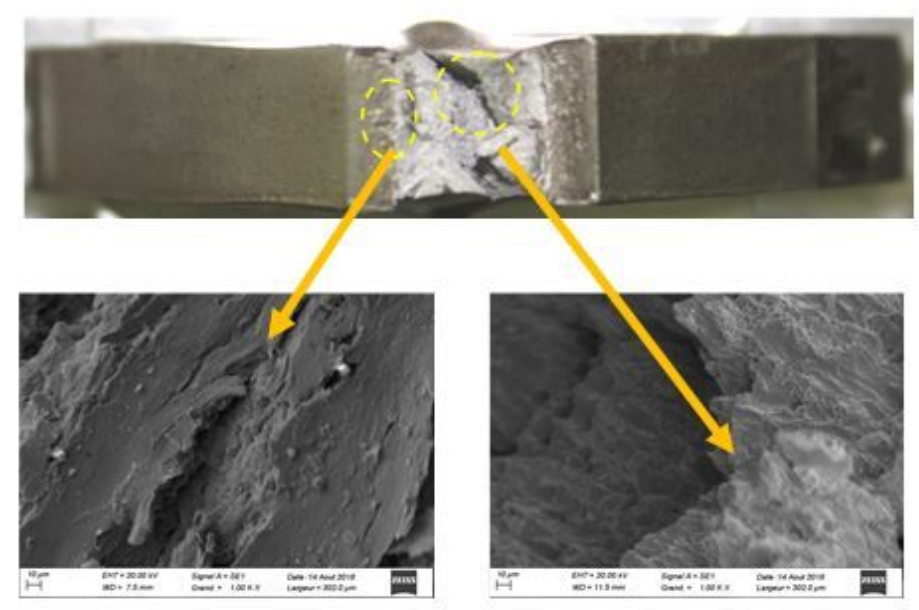

b) $\mathrm{BB}\left(\mathrm{P}_{\mathrm{y}}=10 \mathrm{Kgf}, \mathrm{i}=3\right)$

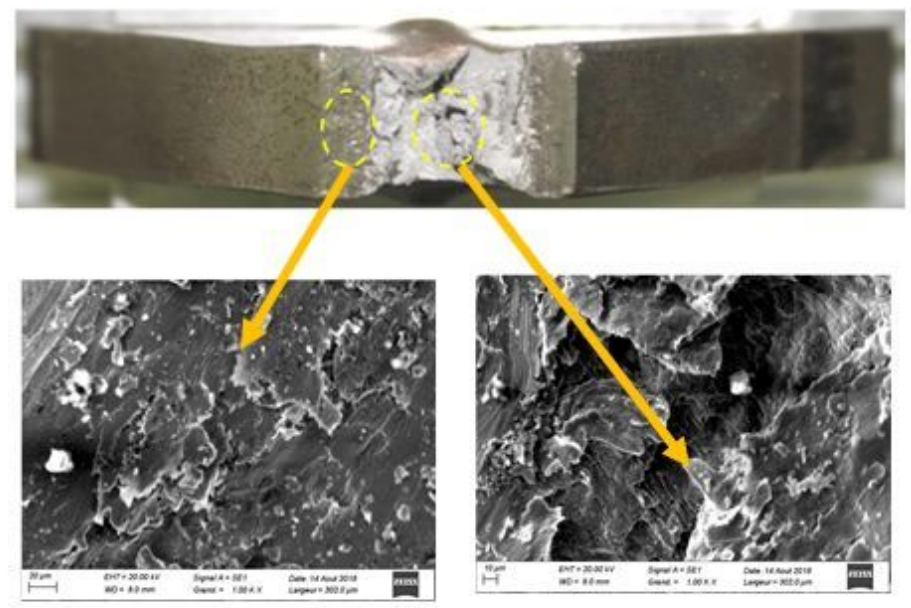

d) $\mathrm{BB}\left(\mathrm{P}_{\mathrm{y}}=20 \mathrm{Kgf} \mathrm{i}=1\right)$

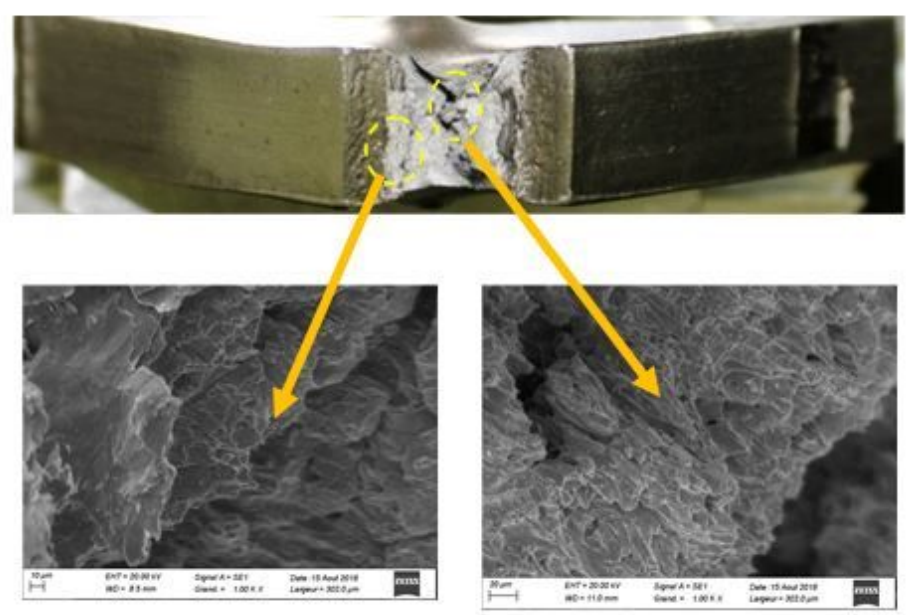

Figure 12

please see the manuscript file for the full caption 